\title{
Una lectura de las políticas de suelo y los modelos urbanísticos madrileños desde mediados de los años 1990: de la liberalización a la resaca inmobiliaria
}

\author{
Eduardo DE SANTIAGO RODRÍGUEZ \\ Doctor Arquitecto por la Universidad Politécnica de Madrid \\ edesantiago@fomento.es
}

Recibido: 24-05-12

Aceptado: 28-09-12

\begin{abstract}
RESUMEN
En este artículo se repasan las políticas y modelos urbanísticos que han dado forma a Madrid en los últimos 30 años, con especial atención a su posicionamiento con respecto a las coordenadas de la coyuntura económica, y particularmente a su papel en la formación de la burbuja inmobiliaria reciente. Por un lado se destaca la articulación entre las políticas y los modelos de los diferentes niveles de gobierno: la liberalización de suelo impulsada desde el ámbito estatal y autonómico, el abandono del planeamiento territorial desde el gobierno regional y la evolución del modelo urbanístico de la ciudad de Madrid a través de los tres Planes Generales elaborados por el Ayuntamiento. En las tres escalas se constata un desplazamiento hacia políticas situadas a medio camino entre el neoliberalismo emergente en la escala global y un neodesarrollismo castizo con características locales propias, junto con una devaluación progresiva del papel del planeamiento como mecanismo regulador de las dinámicas del mercado y como expresión de un consenso político sobre el modelo espacial de la sociedad.
\end{abstract}

Palabras clave: Madrid; burbuja inmobiliaria; planeamiento territorial; urbanismo neoliberal; liberalización del suelo.

\section{A review of land policies and urban planning models in Madrid from mid 1990s: From liberalization to the collapse of the real estate bubble}

\begin{abstract}
This article reviews the policies and planning models that have shaped Madrid in the last 30 years, with particular attention to their positioning with respect to the economic situation, and particularly to its role in the formation of the recent housing bubble. On the one hand, it highlights the link between policies and models of different levels of government, such as land liberalization policy promoted by the State and the regional level; the abandonment of territorial planning by the regional government; and, the evolution of the urban model of the city of Madrid through the three General Urban Plans elaborated by the City Council. It is also possible to point at a displacement in the three spatial scales towards policies located half-way between the emerging neoliberal policies with common features in the global scale and a particular local neo-urban entrepreneurialism, with a gradual devaluation of the role of planning as a regulatory mechanism of market dynamics, and as the expression of a political consensus around the spatial pattern of the local society.
\end{abstract}


Key words: Madrid; housing bubble; regional planning; neoliberal urban planning; land liberalization policy.

\section{Uma leitura das políticas do solo e dos modelos urbanísticos de Madri desde meados dos anos 1990: da liberalização à ressaca imobiliária}

\section{RESUMO}

Neste artigo revisitam-se as políticas e os modelos urbanísticos que deram forma a Madri nos últimos 30 anos, com ênfase espacial à sua posição em relação às coordenadas da conjuntura econômica e, de forma particular, seu papel na formação da bolha imobiliária recente. Por um lado, destaca-se a articulação entre as políticas e os modelos dos vários níveis de governo: a liberalização do solo impulsionada pelo âmbito estatal e autonômico, o abandono do planejamento territorial pelo governo regional e a evolução do modelo urbanístico da cidade de Madri através dos três Planos Gerais elaborados pela Prefeitura. Nas três escalas constata-se um deslocamento rumo a políticas situadas entre o neoliberalismo emergente na escala global e um neodesenvolvimentismo castiço com características locais próprias, unido a uma desvalorização progressiva do papel do planejamento como mecanismo regulador das dinâmicas de mercado e como expressão de um consenso político sobre o modelo espacial da sociedade.

Palavras chave: Madri; bolha imobiliária; planejamento territorial; urbanismo neoliberal; liberalização do solo.

\section{REFERENCIA NORMALIZADA}

De Santiago Rodríguez, Eduardo (2012) "Una lectura de las políticas de suelo y los modelos urbanísticos madrileños desde mediados de los años 1990: de la liberalización a la resaca inmobiliaria". Geopolítica(s). Revista de estudios sobre espacio y poder, vol. 3, núm. 1, 83-116.

SUMARIO: 1 . El largo camino de la liberalización del suelo en la Comunidad de Madrid. 2. La evolución del planeamiento territorial. 3. Los modelos urbanísticos del Plan General de Madrid: del planeamiento de la austeridad al planeamiento neodesarrollista al "límite de la capacidad". 3.1. El Plan General de Madrid de 1985. 3.2. El cambio de coordenadas: la revisión del Plan General de Madrid de 1985 y el Avance de 1990. 3.3. El PG de Madrid de 1997 como modelo de planeamiento neodesarrollista "al límite de la capacidad". 3.4. Las novedades metodológicas del PG de Madrid de 1997. Conclusiones. Bibliografía.

La evolución urbanística de la ciudad de Madrid en las últimas décadas (en la que, sin duda, destacan la burbuja inmobiliaria reciente y la resaca posterior a su estalli$\left.\mathrm{do}^{1}\right)$ es el resultado del juego de fuerzas entre los diferentes agentes que inciden en la producción del espacio urbano, en el marco de unas determinadas coordenadas

\footnotetext{
${ }^{1}$ La limitación del artículo no permite desarrollar las claves del ciclo inmobiliario reciente. Para un análisis del ciclo en España se remite a García Montalvo (2004), Fernández Durán (2006), Rodríguez López (2006), Aguilera y Naredo (2009), Observatorio Metropolitano (2010) y Naredo y Montiel (2011). En el caso del ciclo madrileño: López de Lucio (2003), De Santiago (2006), Observatorio Metropolitano (2007) y Acierno y Mazza (2008).
} 
económicas y sociales, y de unos modelos urbanísticos que se analizarán a continuación. Como se podrá constatar, destaca la progresiva articulación y convergencia entre estas políticas y modelos, en todos los niveles de gobierno, hasta alinearse en una misma dirección donde se combinan aspectos propios del neoliberalismo global emergente con otros característicos de un neodesarrollismo local típicamente hispano basado en el ladrillo.

\section{El largo camino de la liberalización del suelo en la Comunidad de Madrid}

El proceso de liberalización del suelo en España ha tenido un largo recorrido que se remonta - al menos, en su fase más reciente- a mediados de los años 1990 . La breve pero intensa crisis económica experimentada por el país entre 1992 y 1993 tuvo, entre otros, el efecto de provocar el agotamiento y final súbito del primer boom inmobiliario del período democrático que se había desarrollado entre 1985 y 1992. Este momento catártico fue especialmente propicio para realizar un diagnóstico del boom precedente, analizando las causas del incremento desmesurado que habían alcanzado los precios de la vivienda durante esos años. Como se verá, las propuestas derivadas de este diagnóstico provocarían la modificación de la legislación urbanística estatal entonces vigente (la Ley del Suelo estatal de 1990 y del Texto Refundido de 1992), coincidiendo en que la solución se encontraba en la flexibilización del marco normativo de la actividad urbanística, bien a través de la liberalización del suelo (incidiendo en las técnicas de su clasificación), bien a través de la liberalización de su gestión/ejecución (introduciendo la figura del agente urbanizador). El hecho de que además muy poco tiempo después la famosa Sentencia 61/1997 del Tribunal Constitucional sentase las bases de la descentralización competencial plena y efectiva en materia de urbanismo, permitió que las nuevas leyes redactadas por cada Comunidad Autónoma se posicionaran de una u otra forma con respecto al tema del suelo y su liberalización, conformando el menú final de flexibilización de la actividad urbanística mediante la selección y la combinación de las opciones disponibles según resultaba más apropiado para cada contexto autonómico.

A continuación se examinan las principales etapas de este recorrido en el caso de la Comunidad de Madrid, combinando para ello el análisis de la legislación estatal con la específica de la propia Comunidad Autónoma. El objeto de todo ello no es sino contextualizar y describir la conformación de lo que ha sido el marco normativo en el que se ha desarrollado en esta región la burbuja inmobiliaria reciente entre 1997 y 2007.

En la escala estatal, los orígenes de la liberalización pueden remontarse hasta 1993, cuando el Tribunal de Defensa de la Competencia realizó un primer Informe (Tribunal de Defensa de la Competencia, 1993), donde se propuso la creación de una Comisión de Expertos que analizara el problema del suelo en relación al incre- 
mento del precio de la vivienda experimentado durante el boom inmobiliario 19851992 y presentara sus conclusiones al respecto. Atendiendo a ello se creó la Comisión de Expertos sobre Urbanismo, dependiente del Ministerio de Obras Públicas, Transportes y Medio Ambiente (MOPTMA), que elaboró sus trabajos a lo largo de 1994 y elevó sus conclusiones al Gobierno a finales de ese mismo año. El diagnóstico de la Comisión era prácticamente unánime sobre el hecho de que el incremento del precio de la vivienda se debía un desequilibrio entre la oferta y la demanda ${ }^{2}$ : en un contexto de alta demanda como el experimentado durante el boom, era la escasez en la oferta la que había impulsado el ascenso de los precios. Y detrás de esta escasez en la oferta de viviendas estaban las restricciones en la oferta de suelo urbanizado disponible, que se terminaban traduciendo en el incremento del precio del suelo, trasladado posteriormente al precio final de la vivienda. A partir de aquí se proponían dos formas de solucionar el problema, siempre desde el lado de la oferta de suelo:

- La mayor parte de los miembros de la Comisión estimaba que en aquel momento los problemas no se derivaban de la escasez de suelo urbanizable sino de la escasez de suelo urbanizado y, por tanto, centraban el problema en la gestión. De este modo, no se cuestionaban las técnicas de clasificación de suelo vigentes, sino que se focalizaba el problema en el desarrollo y la urbanización del suelo una vez ya clasificado, proponiendo como solución la agilización de la gestión/ejecución y la separación del derecho de la propiedad del suelo del derecho a su desarrollo urbanístico, en línea con la figura del agente urbanizador que se estaba gestando también en aquellas fechas y que muy poco después recogería de modo pionero la Ley 6/1994 Reguladora de la Actividad Urbanística (LRAU) en la Comunidad Valenciana.

- Otra parte minoritaria de la Comisión, sostenía que, además de existir problemas instrumentales de gestión, el problema central eran las restricciones que el planeamiento urbanístico introducía en el mercado del suelo (a través del estricto dimensionado del suelo urbanizable realizado en los planes municipales), pues éstas se terminaban traduciendo en un estrangulamiento de la oferta de suelo urbanizado disponible, lo cual elevaba su precio y finalmente repercutía también en el alza del precio de las viviendas. Desde este punto de vista, había un problema en la legislación vigente, y se hacía necesario reformarla a fondo para acometer una liberalización del suelo, dejar "al mercado que funcione" y "así poner fin a la restricción de su oferta, a la especula-

\footnotetext{
${ }^{2}$ Otros diagnósticos e interpretaciones, en los cuales se afirma justo lo contrario - que es precisamente el precio del suelo el que se deriva del precio de la vivienda, y no al revés- y donde se explican las peculiaridades de los mercados de suelo y de la conformación del precio de la vivienda pueden encontrarse en la bibliografía citada en la Nota 1.
} 
ción sobre el mismo, a la carestía de la vivienda y a las arbitrariedades administrativas" (Tribunal de Defensa de la Competencia, 1993: 41).

Como se verá, si bien ambas fórmulas (liberalización de la gestión-ejecución a través del agente urbanizador, liberalización del suelo) ${ }^{3}$ fueron finalmente introducidas en la legislación estatal ${ }^{4}$, su desarrollo (especialmente de la figura del agente urbanizador) tuvo muy distinta intensidad en las diferentes Comunidades Autónomas $^{5}$. Además de estas dos vías de flexibilización de la actividad urbanística de raíz típicamente liberal, conviene destacar también que ambas coexistieron en la práctica diaria municipal con un neodesarrollismo propiamente hispano basado en el ladrillo, generalizado en casi todos los Ayuntamientos del país, con independencia de su color político. En este neodesarrollismo confluyeron factores estructurales heredados (la cultura de la vivienda en propiedad) con otros característicos del ciclo económico 1997-2007 (la disponibilidad de crédito y financiación abundante y barata, el papel asignado a la vivienda como instrumento de acumulación), así como la elevación a axioma unánimemente compartido de las virtudes de la sobreclasifi-

\footnotetext{
${ }^{3}$ En un primer momento ambas fórmulas se identificaron con posturas políticas diferentes: la liberalización del suelo fue la fórmula "liberal"/"conservadora" y el agente urbanizador la fórmula "progresista"/"socialista", pero posteriormente ambas fueron puestas al servicio del boom inmobiliario. Como señala Gaja, "la LRAU fue una de las últimas leyes aprobadas por el gobierno autonómico del PSPV-PSOE antes de que la derecha ganara las elecciones en 1995. Presentada como una norma que pretendía liquidar una estructura fundiaria urbana pre-moderna (feudal se llegó a decir), fue, quizás por eso mismo, duramente atacada por la derecha desde la oposición. Pero los ataques, bien pronto se verían, eran en realidad fuegos artificiales, retórica electoral. Ganados los comicios, la derecha gobernante se convirtió en su más acérrima defensora. ¿A qué se debe esta metamorfosis?, ¿regeneración social, centrismo político? Nada de eso, pura identidad y convergencia de intereses" (2003: 56-57).

En efecto, según fue avanzando el ciclo inmobiliario ambas fórmulas fueron desvelando sus posibilidades de convergencia, como en el caso valenciano, o la pertinencia de una u otra según el contexto de la estructura de la propiedad local. Como señala el Observatorio Metropolitano, finalmente, "ambos tipos de legislación coexistieron pacíficamente, funcionando como un menú estratégico a elección de las élites autonómicas. Por ejemplo, Valencia, bajo la dirección del Partido Popular, siguió utilizando la LRAU del PSOE, en tanto ariete para eliminar las barreras a la acumulación de capital que supone una estructura de propiedad rústica atomizada. Sin embargo, en el caso de Castilla y León, ese mismo partido optó por un modelo de liberalización de suelo con clara intención de rehabilitar la figura del propietario de suelo agrícola, que constituye una de sus bases tradicionales" (2010:310).

${ }^{4}$ Como se ha comentado, el agente urbanizador se introdujo primero en la escala autonómica, de modo pionero en la Comunidad Valenciana — gobernada entonces por el PSOE- mediante la LRAU de 1994, y posteriormente en otras CCAA, con independencia de su signo político - entre ellas, en la de Madrid, mediante la Ley de 2001-. En la escala estatal la figura fue incorporada y desarrollada en la Ley 8/2007 de Suelo, aprobada por el PSOE.

Respecto a la liberalización del suelo fue introducida por el PP primero en la escala estatal (1998 y 2000), y posteriormente se difundió a las CC AA —en Madrid se incorporó también en la Ley de 2001-.

${ }^{5}$ En la Comunidad Valenciana y en Castilla La Mancha, la fórmula del agente urbanizador se convirtió en el sistema exclusivo de ejecución del planeamiento, pero en el resto de comunidades convivió con los sistemas tradicionales (compensación, expropiación, etc.).
} 
cación de suelo y del planeamiento al límite de la capacidad (pues supuestamente la sobreoferta - primero de suelo, y después de vivienda- haría disminuir los precios), el recurso a la financiación municipal a través del urbanismo, etc.

Regresando al hilo histórico, el Consejo de Ministros, con fecha 13/01/1995, aprobó un documento titulado "Reformas legislativas para atajar el problema de la escasez de suelo", que había sido elaborado por el MOPTMA tomando como base las recomendaciones de la parte mayoritaria de la Comisión de Expertos. En él se trazaban las líneas generales de actuación para solventar el problema del suelo, partiendo de la base de que lo que escaseaba era el suelo urbanizado y que la cantidad de suelo urbanizable disponible entonces en España era más que suficiente para atender a la demanda de vivienda prevista en los quince años siguientes ${ }^{6}$. Por ello, las actuaciones que se planteaban pretendían favorecer el proceso de transformación del suelo simplemente clasificado como urbanizable en suelo efectivamente urbanizado, consistiendo en pequeños retoques legislativos de la Ley del Suelo estatal entonces vigente para favorecer la acción urbanizadora, planteando mecanismos similares al del "agente urbanizador" recién introducido en aquel entonces y de forma pionera por la LRAU valenciana, con el objeto de que "los promotores y constructores que deseen urbanizar y edificar sustituyan a los propietarios de suelo que no puedan o no deseen hacerlo [...] tras el consiguiente trámite de concurrencia pública [subasta]" (Tribunal de Defensa de la Competencia, 1993: 42) ${ }^{7}$.

Sin embargo, estas propuestas - fieles a la opinión mayoritaria de la Comisión de Expertos - fueron duramente criticadas por el nuevo Informe del Tribunal de la Competencia de 1995, según el cual:

España padece agudamente los efectos derivados de la escasez de suelo pese a que este factor es relativamente abundante en términos físicos. Ello se debe a la existencia de una legislación sobre la materia sumamente intervencionista que restringe artificialmente la oferta de suelo hasta el punto de conseguir que haya una gran falta

\footnotetext{
${ }^{6}$ Apoyándose en un Informe interno del propio MOPTMA de Diciembre de 1995 "Disponibilidad de Suelo Urbanizable en los municipios de más de 20.000 habitantes. Previsiones de planeamiento urbanístico y relación con las necesidades de suelo urbanizado".

${ }^{7}$ La concepción original del agente urbanizador -impulsada intelectualmente en buena medida por García Bellido (1993), Gerardo Roger y Luciano Parejo- fue posteriormente desvirtuándose, sobre todo en la práctica real, contribuyendo a la turbo-urbanización del territorio.

Analizando la LRAU, Gaja (2003: 57) señala: "La LRAU se construye a partir de dos hipótesis explícitas: la primera es que los propietarios son el principal obstáculo que se opone a la modernización del sector inmobiliario - modernización es el eufemismo al uso para designar un funcionamiento ajustado a las reglas de la economía de mercado liberalizado, es decir a un capitalismo sin regulaciones protectivas-; y la segunda, que el suelo es el principal factor de carestía de los productos inmobiliarios. Amunicionados con estas dos hipótesis por todo bagaje conceptual, la conclusión es clara: se impone acabar con los terratenientes clásicos, devenidos capa parasitaria. Y a ello se dedica con denuedo la LRAU, a anular la posición hegemónica de los propietarios del suelo y a auspiciar una política de fomento a toda costa de la producción de suelo urbanizado".
} 
del mismo y que, por consiguiente, su precio sea muy elevado. Esta carestía del suelo es origen de graves distorsiones. Al ser el coste del suelo un componente fundamental del precio de la vivienda, los altos precios de suelo se traducen en precios de la vivienda muy elevados, lo que dificulta el acceso a este bien esencial (Tribunal de Defensa de la Competencia, 1993: 35).

Abundando en la culpabilidad del suelo, se le convertía en el chivo expiatorio de todos los males urbanísticos conocidos: "por otra parte, la escasez de suelo afecta a la calidad de vida de los ciudadanos al condicionar la configuración urbanística de las ciudades, donde la falta de espacio propicia que la densidad de población sea mayor, que sea menor el tamaño de las viviendas, que haya menos espacios libres, que el tráfico sea más difícil, etc." (Tribunal de Defensa de la Competencia, 1993: 37). De modo que el Informe terminaba concluyendo:

[S] i se quiere acabar con la carestía del suelo y de la vivienda es necesario abandonar el espíritu intervencionista y planificador con que la Administración regula y actúa en la actualidad y optar por la liberalización de la legislación del suelo, recurriendo a unas reglas objetivas y transparentes que conjuguen el respeto a los objetivos públicos con el funcionamiento eficiente del mercado (Tribunal de Defensa de la Competencia, 1993: 43).

Estas declaraciones del Tribunal de Defensa de la Competencia y los reclamos en el mismo sentido del bloque inmobiliario ${ }^{8}$ encontraron un contexto especialmente propicio con la llegada del Partido Popular (PP) al gobierno central tras las elecciones generales de 1996. Comenzó entonces una senda progresiva hacia la liberalización del suelo, primero de forma tímida mediante el paquete de Medidas Urgentes Liberalizadoras en materia de Suelo y Colegios Profesionales introducido en el Real Decreto 5/1996, que culminó en la aprobación de la Ley 6/1998 sobre Régimen de Suelo y Valoraciones y, sobre todo (tras la obtención de la mayoría absoluta parlamentaria en las elecciones del año 2000) en el Real Decreto 4/2000 de Medidas Urgentes de Liberalización en el Sector Inmobiliario y de Transportes.

Así, la Ley 6/1998, dentro de las importantes restricciones competenciales en materia de urbanismo que dibujó la Sentencia del Tribunal Constitucional de 1997 recogía la idea de que todo el territorio - salvo aquellas zonas que deban ser justificadamente protegidas - es susceptible de ser urbanizado. En el Preámbulo podía leerse que su pretensión era "facilitar el aumento de la oferta de suelo, haciendo posible que todo el suelo que todavía no ha sido incorporado al proceso urbano, en

\footnotetext{
${ }^{8}$ La cantidad de suelo urbanizable clasificado siempre parecía sistemáticamente insuficiente a las empresas inmobiliarias, a no ser que éstas fuesen a su vez grandes propietarias de suelo-y por tanto beneficiarias también de su monopolio-, lo cual no ha sido habitual hasta muy recientemente. Véanse al respecto las Notas 13 y 19 .
} 
el que no concurran razones para su preservación, pueda considerarse como susceptible de ser urbanizado".

No obstante, y, a pesar de estas declaraciones explícitas a favor de la liberalización del suelo, la falta de una mayoría absoluta parlamentaria hizo que Ley se limitase en la práctica a atribuir al suelo no urbanizable un carácter residual, lo cual sin duda resultó conceptualmente importante, pero no alteró sustancialmente la metodología tradicional de clasificación del suelo ${ }^{9}$.

En realidad, el cambio trascendental se produjo tras la rotunda victoria del PP en las elecciones de Marzo de 2000, con las medidas urgentes de liberalización del RD 4/2000, mediante el cual, según se comentaba en su Preámbulo:

[Se] pretenden corregir las rigideces advertidas en el mercado como consecuencia del fuerte crecimiento de la demanda y la incidencia en los productos inmobiliarios del precio del suelo, condicionada a su vez por la escasez de suelo urbanizable. En consecuencia, la reforma que se introduce habrá de incrementar la oferta del suelo al eliminar aquellas previsiones normativas en vigor que por su falta de flexibilidad pudieran limitarla, trasladando este efecto positivo al precio final de los bienes inmobiliarios $^{10}$.

En base a estas intenciones, el RD 4/2000 consiguió la liberalización efectiva del suelo - mediante un sutilísimo retoque del régimen urbanístico de la propiedad del suelo que había establecido la Ley de 1998- y con ella alteró de forma radical el modelo canónico de planeamiento que había estado vigente en España durante 40 años.

La liberalización se realizó a través de la nueva definición de suelo no urbanizable, derivada de la supresión de la famosa "coletilla" $"$ de la Ley de 1998 mediante

\footnotetext{
${ }^{9}$ Véase al respecto Rullán (1999).

${ }^{10}$ Real Decreto-ley 4/2000, de 23 de junio, de Medidas Urgentes de Liberalización en el Sector Inmobiliario y Transportes (Boletín Oficial del Estado, $\mathrm{n}^{\circ} .151$ de 24 de junio de 2000, páginas 22436 a 22438).

${ }^{11}$ La definición del Suelo No Urbanizable que se establecía en el artículo 9 de la Ley 6/1998 era la siguiente: "Tendrán la condición de suelo no urbanizable, a los efectos de esta Ley, los terrenos en que concurran alguna de las circunstancias siguientes:

1. Que deban incluirse en esta clase por estar sometidos a algún régimen especial de protección incompatible con su transformación de acuerdo con los planes de ordenación territorial o la legislación sectorial, en razón de sus valores paisajísticos, históricos, arqueológicos, científicos, ambientales o culturales, de riesgos naturales acreditados en el planeamiento sectorial, o en función de su sujeción a limitaciones o servidumbres para la protección del dominio público.

2. Que el planeamiento general considere necesario preservar por los valores a que se ha hecho referencia en el punto anterior, por su valor agrícola, forestal, ganadero o por sus riquezas naturales, así como aquellos otros que considere inadecuados para un desarrollo urbano" (el resaltado es mío).

La modificación introducida por el RD 4/2000 consistió simplemente en eliminar la parte resaltada. Eliminando sólo esta frase se transformaron radicalmente las bases conceptuales del planeamiento en España, pues se suprimió la potestad ordenadora del planeamiento general que hasta entonces - desde la primera
} 
la cual todavía se había permitido que el planeamiento general incluyera como no urbanizables los terrenos que se considerasen inadecuados para el desarrollo urbano. De modo que a partir del RD 4/2000 sólo quedaban excluidos de la posibilidad de ser urbanizables los terrenos que fuera necesario proteger por sus valores (paisajísticos, históricos, arqueológicos, científicos, ambientales, culturales, agrícolas, forestales, ganaderos o por sus riquezas naturales), los inadecuados por presentar riesgos naturales acreditados o los sujetos a limitaciones o servidumbres para la protección del dominio público. En la práctica esto implicaba la máxima liberalización del suelo posible ${ }^{12} \mathrm{y}$ también que, de un plumazo, los suelos no urbanizables comunes, que constituían la mayor parte de la superficie en casi todos los términos municipales españoles, perdieran la razón por la que se clasificaron como tales y que por tanto, en caso de revisarse el planeamiento de acuerdo a la nueva legislación, pasasen a ser potencialmente urbanizables.

De este modo, el RD 4/2000 abrió la posibilidad de que, una vez delimitada la ciudad consolidada y preservados ciertos fragmentos del medio natural merecedores de protección o afectados por las infraestructuras, se entendiera que el resto del suelo era potencialmente urbanizable y por tanto susceptible de ser desarrollado por sus propietarios, a quienes - desde esa nueva perspectiva - no puede sustraerse este derecho ${ }^{13}$.

La liberalización introducida por esta reforma era conceptualmente tan profunda (al invertir la tradicional sujeción de los derechos de la propiedad a la función social de la misma, que había caracterizado toda la legislación urbanística española desde 1956), que no pudo sostenerse mucho tiempo, de modo que se rectificó mediante la

Ley de Suelo de 1956- había incluido la posibilidad de establecer un determinado modelo urbano, en base al cual determinados suelos podían ser considerados como "inadecuados para el desarrollo urbano", limitando por tanto el ius aedificandi y regulando el suelo conforme a la función social de la propiedad.

Esta capacidad regulatoria y ordenadora del planeamiento, basada en la función social de la propiedad, fue por tanto desplazada por los derechos de los propietarios de suelo.

${ }^{12}$ A pesar de ello, desde la máquina inmobiliaria se ha seguido reclamando interesadamente - al menos hasta el cambio de ciclo a mediados de 2007- más liberalización... ¿de qué?, ¿de los suelos protegidos?

${ }^{13}$ Por el contrario, según la perspectiva que había sido tradicional desde la Ley de 1956, "la propiedad sería por naturaleza rústica. Su conversión en urbana (y la plusvalía correspondiente) no entraría dentro de las facultades de goce y disposición del propietario, sino que le sería otorgada (en las condiciones marcadas por la ley) por los poderes públicos competentes" (Menéndez Rexach, 2006: 260).

Como se ha apuntado, la perspectiva de la opción del "agente urbanizador" es también diferente: en este caso el propietario de suelo clásico es visto como un obstáculo para la apertura del proceso de urbanización a la iniciativa empresarial de los agentes profesionales (promotores) no propietarios de suelo. Véase a este respecto la Nota 8 y Gaja (2003).

En realidad, el debate central subyacente en las reformas legislativas de todo el período analizado se resume en estas tres perspectivas y finalmente en determinar cuál es el papel que deben jugar los propietarios de suelo en la actividad urbanística. De modo que cada una de las perspectivas expresa determinados intereses. En función de cada contexto concreto, los intereses del bloque local hegemónico (en unos casos pequeños propietarios; en otros, pequeñas empresas promotoras no propietarias de suelo; en otros, grandes promotoras que también son propietarias, etc.) presionan para imponer una u otra perspectiva. 
Ley 10/2003, de 20 de mayo, donde se volvió a reintroducir nuevamente la famosa "coletilla"14, devolviendo así al planeamiento su capacidad de ordenar el territorio y de delimitar socialmente los derechos de la propiedad privada. No obstante $-\mathrm{y}$ en pleno fragor del boom inmobiliario-, la liberalización había ganado ideológicamente la batalla, al imponerse culturalmente junto a las ideas neodesarrollistas de crecimiento hasta la saturación, las bondades de la sobreclasificación, etc.

En la escala autonómica, la Ley 9/2001 del Suelo de la Comunidad de Madrid ${ }^{15}$ abunda todavía más en el modelo de clasificación establecido por la legislación estatal, completando y perfeccionando para esta Comunidad Autónoma el camino de la liberalización del suelo emprendido a escala estatal por el RD 4/2000. Las novedades más destacables en relación a la clasificación del suelo de la Ley madrileña de 2001 son: la aparición de categorías primarias en suelo urbano (consolidado y no consolidado) y en suelo urbanizable (sectorizado y no sectorizado), y, sobre todo, la definición del suelo no urbanizable, que pasa a ser denominado como Suelo No Urbanizable de Protección (SNUP), despareciendo el suelo No Urbanizable Común (SNUC). Este suelo no urbanizable de protección está constituido, en la línea introducida a nivel estatal por el RD 4/2000, exclusivamente por los terrenos que sea necesario sustraer del desarrollo urbano por estar sometidos a algún régimen especial de protección incompatible con su transformación de acuerdo con el planeamiento regional, territorial o la legislación sectorial, o en razón de unos valores concretos que en todo caso es necesario justificar.

Por el contrario, dentro del suelo urbanizable se establecen dos categorías: el urbanizable sectorizado (que viene a coincidir con el urbanizable tradicional, al estar integrado por los terrenos que el planeamiento general prevea expresamente que deben transformarse en suelo urbano y que, a tales efectos, se dividen en recintos denominados sectores) y el no sectorizado, que es el que asume a partir de ahora el carácter residual o sobrante (es decir, el que no es ni urbano ni no urbanizable de protección) que antes absorbía el suelo no urbanizable común. Aunque esto no signifique que todo él vaya a urbanizarse, la diferencia está en que ese suelo "sobrante" - que generalmente es el de mayor dimensión - era antes no urbanizable y ahora tiene la vocación de ser urbanizable, a la simple espera de las iniciativas de su sectorización, para poder convertirse así en urbanizables a "demanda" del mercado.

Una vez aprobada, la Ley 9/2001 fue duramente atacada, tanto por la oposición política como por las organizaciones ecologistas, que propusieron derogarla. En las elecciones autonómicas de mayo de 2003 el PP obtuvo 55 diputados, frente a los 56

\footnotetext{
${ }^{14}$ Quedando con la siguiente redacción: "así como aquellos otros que considere inadecuados para el desarrollo urbano, bien por imperativo del principio de utilización racional de los recursos naturales, bien de acuerdo con criterios objetivos de carácter territorial o urbanístico establecidos por la normativa urbanística". ${ }^{15}$ Ley 9/2001, de 17 de julio, del Suelo de la Comunidad de Madrid (BOCM 27 de julio de 2001, corrección de errores BOCM 24 de enero de 2002).
} 
que sumaron PSOE e IU. Todo apuntaba a un cambio de gobierno, y a que, en pleno fragor inmobiliario, éste hubiese muy posiblemente derogado o modificado dicha Ley, pero la abstención de dos diputados socialistas en la investidura del candidato del PSOE lo impidió. Se produjo un escándalo político, en el que hubo acusaciones de transfuguismo y corrupción, pero aunque se sospechó de la existencia de una trama inmobiliaria y urbanística, el empate técnico en la comisión de investigación creada al efecto impidió también la aprobación de las conclusiones ${ }^{16}$. Finalmente, fue necesario convocar nuevos comicios en octubre de 2003, que venció por mayoría absoluta el PP, siendo elegida como Presidenta de la Comunidad de Madrid Esperanza Aguirre - relevando a Alberto Ruiz Gallardón, que lo había sido entre 1995 y 2003 - abiertamente defensora de las políticas (neo)liberales.

En el ámbito urbanístico, por si la liberalización del suelo realizada previamente no hubiese sido suficiente, a partir de 2003 se fueron introduciendo nuevas modificaciones para "liberalizar" incluso el suelo protegido, como las incluidas en la Ley $3 / 2007$ de 26 de Julio $^{17}$ (art. 14), que contemplaban la posibilidad de autorizar en suelos rurales -además de actividades agrícolas, forestales, cinegéticas y análogas - la elaboración de productos primarios y el uso de vivienda como accesorio; o las contenidas en la Ley $7 / 2007$ de 21 de Diciembre ${ }^{18}$ (Art. 10.2), para permitir la implantación de equipamientos, infraestructuras y servicios públicos de la Administración en suelos protegidos y no sectorizados. Todo ello ha culminado en 2012 con la propuesta de un anteproyecto de Ley de Urbanizaciones Rurales Sostenibles, en uno de cuyos borradores se llegaban incluso a plantear directamente urbanizaciones -eufemísticamente denominadas sostenibles- en suelos protegidos. No obstante, lo más significativo de esta última etapa — dado que poco más podía avanzarse ya respecto a 2001 en la liberalización del suelo- ha sido la eliminación de la figura del agente urbanizador y, como después se analizará, la desaparición de la escena del planeamiento territorial en la región metropolitana madrileña.

A nuestro juicio, el verdadero significado de toda esta deriva a medio camino entre el neodesarrollismo y el neoliberalismo ha sido la puesta en carga -o el establecimiento de las bases para que fuese posible hacerlo- de la mayor parte del suelo de la región, para que de este modo - y manteniendo los privilegios de las operaciones mejor situadas en la parrilla de salida - pudieran romperse -mediante esa oferta cuasi-ubicua de suelo- los posibles monopolios parasitarios que sobre otros suelos pudieran ejercerse, evitando al mismo tiempo la capacidad de interferir

\footnotetext{
16 La cronología de la crisis electoral de 2003 puede seguirse en elmundo.es [URL: $<$ http://www.elmundo.es/especiales/2003/10/madrid/elecciones/cronologia.html $>$. Consultado el 10 de Abril de 2012].

${ }^{17}$ Ley 3/2007, de 26 de julio, de Medidas Urgentes de Modernización del Gobierno y la Administración de la Comunidad de Madrid (BOCM 30 de julio de 2007).

${ }^{18}$ Ley 7/2007, de 21 de diciembre, de Medidas Fiscales y Administrativas (BOCM 28 de diciembre de 2007).
} 
en la toma de nuevas posiciones a futuro por parte de los principales agentes, pues cualquier posición monopolística indeseada estrangularía no sólo su negocio ${ }^{19}$, sino también esa turbo-urbanización pretendida que supuestamente haría descender los precios en toda la región.

En la misma línea, Gago señalaba también que entre los conceptos manejados:

[E]l principal sin duda es la confianza prácticamente ilimitada no tanto en la "economía de mercado" como en la capacidad del negocio inmobiliario para - a través del mercado - organizar del modo más eficiente la ocupación y el uso del territorio. La antigua visión de la ciudad como lugar de los negocios abre así el paso a un nuevo entendimiento - el negocio de hacer ciudad-, en donde ésta se concibe directamente no ya como lugar, sino como objeto propio de negocio e, incluso, como simple excrecencia del mismo (2005: 6).

En este sentido, no hay que olvidar que una coordenada fundamental del modelo de acumulación de los últimos años ha sido la conversión de la vivienda — por encima de su valor de uso o superponiéndose a él- en un simple instrumento de capitalización hacia el cual se ha canalizado el ahorro y los excedentes de capital de los particulares (nacionales o extranjeros) y de las empresas del sector, para posteriormente convertirla junto al suelo en el objeto más rentable de las prácticas especulativas; de modo que la urbanización se ha entendido no sólo o prioritariamente al servicio de las necesidades de alojamiento, sino como simple soporte de la construcción de viviendas devenidas en instrumentos de capitalización o especulación. Todo lo cual no es sino un reflejo del cambio producido en el modelo de acumulación español y madrileño, y del papel protagonista que ha jugado en el mismo el sector inmobiliario hasta el estallido de la burbuja en 2007: en efecto, del urbanismo puesto al servicio del despliegue prioritario de la "modernización industrial" desarrollista se ha pasado al urbanismo al "servicio de la economía monetaria" (González García y Hernández Aja, 2007), a la mera disposición de suelo para la

\footnotetext{
${ }^{19}$ Esto podría explicar el poco éxito de la figura del agente urbanizador en la Comunidad de Madrid, y el aplauso del bloque inmobiliario regional a su desaparición mediante la reforma de la Ley 9/2001 introducida por la Ley 3/2007 de Medidas Urgentes de Modernización, en cuyo Preámbulo se justifica porque "durante su existencia no ha demostrado su eficacia y cuyas funciones podrían entrar en colisión con el derecho de propiedad de numerosos ciudadanos".

En realidad, según indican los datos del Atlas Estadístico de las Áreas Urbanas en España (Ministerio de Fomento, 2009), en el área urbana de Madrid, una parte considerable del suelo ya está en manos de empresas y promotoras, así el $40,3 \%$ del suelo urbano no edificado ya es propiedad de personas jurídicas - frente al $18,9 \%$ de personas físicas-y en el suelo rústico éstas disponen ya del $25,1 \%$.

Por el contrario, en la Comunidad Valenciana — paradigma de la liberalización de la gestión del suelo a través del agente urbanizador, a costa de los pequeños y medianos propietarios- la atomización de la estructura de la propiedad era mucho mayor, como muestra el hecho que personas físicas sean titulares del $37,8 \%$ del suelo urbano no construido y del $72,4 \%$ del rústico.
} 
construcción de un armatoste inmobiliario de acumulación familiar y empresarial cuando no de mera especulación.

\section{La evolución del planeamiento territorial}

Teniendo en cuenta su importancia económica y demográfica, su controlada dimensión, así como la feliz coincidencia que se da en la Comunidad de Madrid entre los límites administrativos y funcionales de la región ${ }^{20}$, llama la atención el hecho de que ésta carezca actualmente de cualquier tipo de planeamiento de escala territorial, (metropolitana o regional) a pesar de que la Ley de Medidas de Política Territorial, Suelo y Urbanismo ${ }^{21}$ estableciera en una fecha tan lejana como 1995 toda una batería de instrumentos de ordenación territorial, cuya pieza era el Plan Regional de Estrategia Territorial (PRET), que supuestamente viene elaborándose desde entonces y que tras dos intentos abortados ${ }^{22}$ permanece estancado desde hace una década.

Realizando un breve repaso al planeamiento territorial en la región, tras la desmesura de las propuestas megalómanas que se hicieron durante los últimos tiempos del franquismo, la profunda crisis económica de 1973-1985 introdujo la idea de que el crecimiento metropolitano se detendría súbitamente, estabilizándose la región en términos demográficos y espaciales. El territorio pasó a entenderse entonces como problema heredado de la etapa anterior, volviéndose la mirada hacia la cultura de la austeridad e incidiendo en la protección del medio natural, la recuperación de la ciudad consolidada y la sutura de las heridas que el crecimiento desarrollista había provocado.

Tras la recuperación económica posterior a entrada en la CEE en 1986, comenzaron a entreverse unas nuevas coordenadas de crecimiento económico, enunciadas como el "ensayo de salida de la crisis" y que fueron rápidamente asumidas por el gobierno regional, entonces en manos del PSOE. Respondiendo a este contexto se arrinconó la idea de la austeridad — que había presidido el planeamiento durante la segunda mitad de los 1970 y primeros 1980 - y dejó de entenderse el territorio como problema, para verlo como oportunidad, apostándose por un nuevo modelo territorial, basado en la recuperación de las redes viarias de alta capacidad y el planteamiento de espacios para las nuevas actividades económicas emergentes (terciario, comercio, ocio, etc.). Así, entre 1986 y 1995 se elaboraron todo un con-

\footnotetext{
${ }^{20}$ Lo que supone la ventaja de que exista un órgano de gobierno a escala de la región urbana. Por la razón contraria, actualmente comienza a resultar problemático el incipiente desbordamiento hacia Castilla La Mancha .

${ }^{21}$ Ley 9/1995, de 28 de marzo, de Medidas de Política Territorial, Suelo y Urbanismo (BOCM de 11 de abril de 1995).

${ }^{22}$ Bases del Plan Regional de Estrategia Territorial de 1995 y 1998.
} 
junto de documentos, planes y estrategias territoriales que fueron definiendo de modo cada vez más elaborado este nuevo "territorio inteligente", planteando la colonización de las grandes redes viarias (M-40, M-50) con toda una serie de nuevas centralidades y áreas de oportunidad, fundamentalmente de iniciativa pública. El objetivo era triple: 1) aprovechar la accesibilidad de los nuevos territorios descubiertos por las infraestructuras; 2) generar nuevas actividades productivas y de centralidad en las zonas más desfavorecidas, contribuyendo así al reequilibrio regional (norte/sur y centro/periferia); y 3 ) rentabilizar públicamente las plusvalías del suelo generadas por el trazado de las nuevas infraestructuras.

Figura la. Estrategia de implantación de nuevas centralidades y espacios para actividades económicas avanzadas colonizando las M-40 y M-50 en las Estrategias de Planeamiento Territorial de 1991

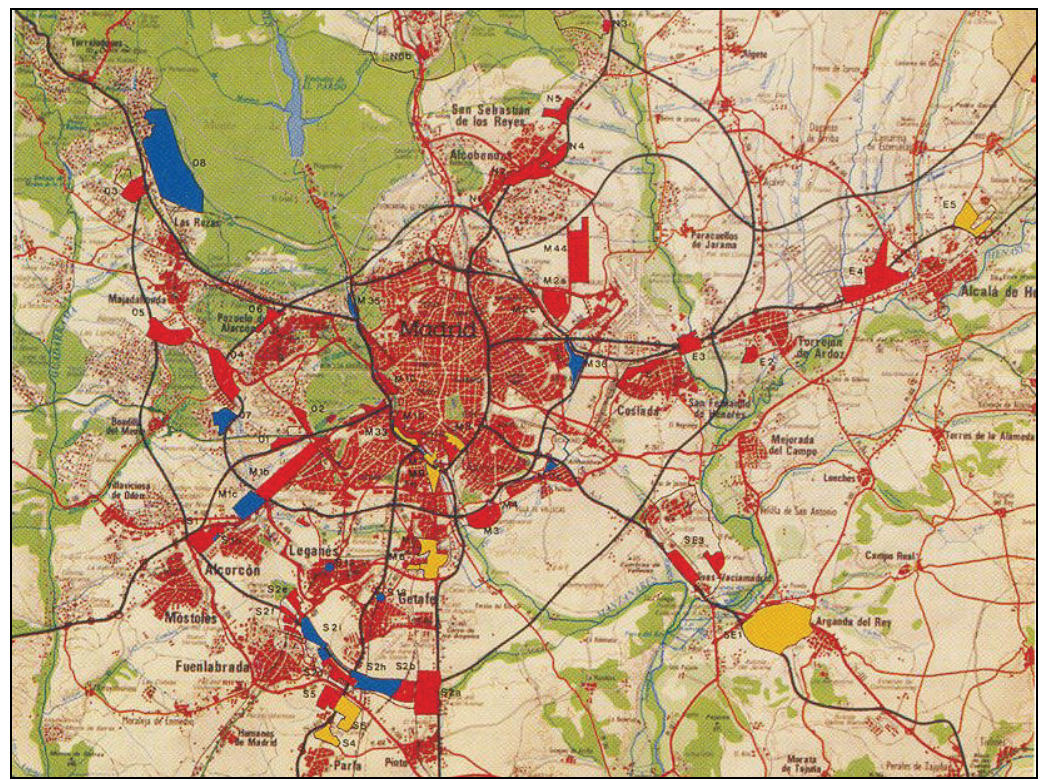

Fuente: De Terán (1999: 138).

Sin embargo, estos planes se desbaratarían por la repentina crisis económica desatada en 1992 y también porque se confió excesivamente en que el simple dibujo (y reserva de suelo) de espacios talismán para actividades avanzadas y nuevas centralidades bastaría para que estas florecieran por doquier, algo que la crisis desmintió rápidamente. Como además se había sobrevalorado el liderazgo y capacidad de la iniciativa pública para acometer estos nuevos desarrollos, el hundimiento de la demanda hizo que muchos de estos proyectos hubieran de redefinirse para evitar el desastre financiero, adaptándolos a los requerimientos estrictos del merca- 
do; perdiendo con ello su sentido original, sacrificando parcialmente sus objetivos y desaprovechando para siempre aquellas oportunidades que la M-40 y M-50 descubrieron sobre el territorio.

Figura 1 b. Imagen final de la región metropolitana con la malla reticular de autopistas y las nuevas UDEs en el Planeamiento Territorial de 1996

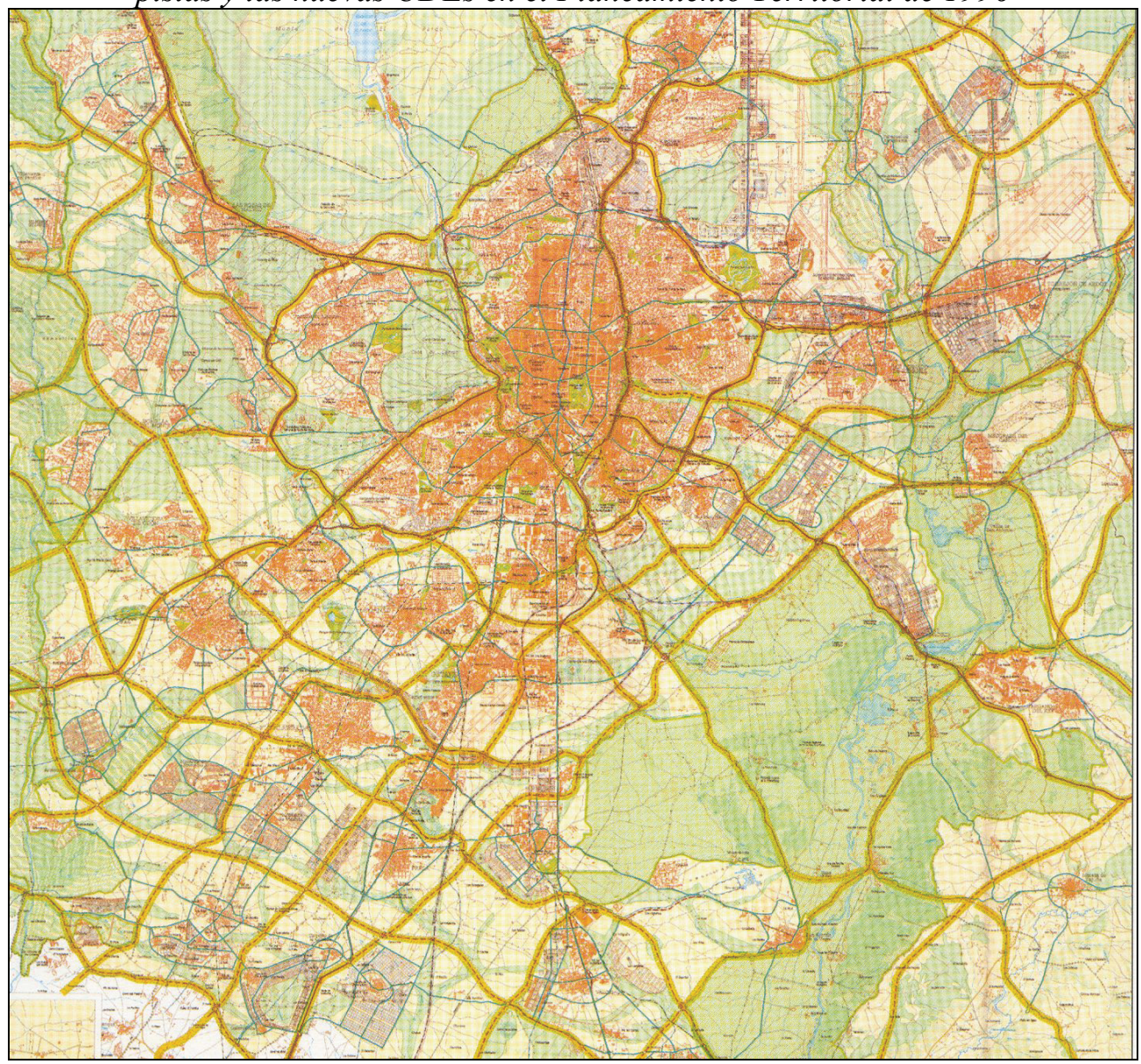

Fuente: Comunidad de Madrid (1998). Bases del Plan Regional de Estrategia Territorial de la Comunidad de Madrid.

En las elecciones autonómicas de 1995 se produjo la victoria del Partido Popular (PP), que comenzó a plantear un modelo fuertemente expansivo, más por convic- 
ción ideológica ${ }^{23}$ que porque realmente se imaginasen o anticipasen entonces los fenómenos que muy poco tiempo después iban a generar una intensa demanda de oficinas con nuevas pautas de asentamiento o a desatar el boom inmobiliario (tales como el fuerte crecimiento económico, la barra libre de liquidez para los préstamos hipotecarios a tipos bajos de interés, la inmigración, etc.). El caso es que el modelo relativamente ajustado y con afán reequilibrador que se había venido diseñando durante la década anterior fue sustituido por un modelo que daba por sentados los procesos dispersivos y la explosión urbana, proponiendo cubrir la práctica totalidad de la región con una malla de autopistas (de $5 \times 5 \mathrm{~km}$ ) sobre la cual se apoyarían las denominadas UDEs (Unidad de Desarrollo Equilibrado), grandes piezas residenciales dimensionadas para acoger unas 500.000 viviendas $^{24}$ en total. La metáfora propuesta, en palabras del entonces Director General, era un tablero de ajedrez, "donde las casillas [...] tienen una equivalencia de accesibilidad y en donde los recorridos ofrecen alternativas dispersadoras y liberalizadoras de la congestión" (Ortiz, 1997), pretendiendo con ello reconducir la estructura radioconcéntrica del área metropolitana hacia una morfología reticular. Pero lo importante, no era esta nueva malla reticular de autopistas - aunque visualmente resultase muy impactante-, sino la plasmación literal de la idea de "territorio red": una red de transporte superpuesta al territorio articulando en un mismo organismo funcional piezas espacialmente discontinuas y físicamente aisladas.

La geometría de este modelo - que no su lógica - entró en clara contradicción con el trazado radioconcéntrico de las nuevas autopistas radiales que hizo casi al mismo tiempo el gobierno central (curiosamente del mismo partido político) y fue abandonado hacia 1999. Desde entonces hasta la actualidad ha discurrido casi una década, durante la cual no se ha hecho público ningún documento de planificación territorial.

¿Significa esto que la región madrileña carezca de modelo territorial? En absoluto. A pesar de no haber sido dibujado, la Ley del Suelo aprobada en 2001 contiene un modelo clarísimo, al permitir que los Planes Generales municipales clasifiquen como urbanizables casi todos los suelos de la región, excepto aquellos protegidos que es necesario preservar de la urbanización por sus valores naturales, arqueológicos, etc. De manera que, en realidad el modelo territorial madrileño - en plena coherencia con la ideología neoliberal- es que no exista modelo, un papel en blanco. El urbanismo neoliberal es el de la no injerencia en las dinámicas del mer-

\footnotetext{
${ }^{23}$ Se consideraba que la dispersión, aunque indeseable, era poco menos que inevitable, como consecuencia del crecimiento económico, el incremento de la movilidad, y la redistribución de hogares en la región - como consecuencia también de la disminución del tamaño medio del hogar y del incremento de superficie disponible por habitante- aunque no hubiese previsto un incremento demográfico relevante.

${ }^{24}$ En este aspecto este Plan anticipó una cifra muy aproximada al crecimiento que se produciría después, por factores bien distintos.
} 
cado: basta con que las redes conecten las nuevas piezas con la estructura de movilidad regional, dejando que sea el mercado quien decida qué piezas resultan más atractivas para ser desarrolladas y en qué condiciones. De este modo, el planeamiento territorial se retira de la escena, para ceder el protagonismo a los Planes Generales municipales.

Así, sin que existiera una formulación explícita del modelo territorial, y por tanto sin criterios de coordinación ni coherencia territorial, sólo entre 1998 y 2004 se aprobaron 21 Planes Generales de escala municipal en los 29 municipios del área metropolitana. Además, la mayoría de estos planes optan por el modelo neodesarrollista introducido por el Plan General de Madrid de 1997: el dimensionamiento del suelo del municipio "al límite de la capacidad"; es decir, el planteamiento del máximo crecimiento posible en cada municipio, sin determinar un plazo temporal para su colmatación. En realidad, el mosaico formado por la yuxtaposición del conjunto de Planes Generales es el verdadero plano de la estrategia territorial madrileña: un mercado de oferta de suelo sobredimensionada para que los agentes inmobiliarios desarrollen, en función de las oportunidades del territorio (básicamente de su accesibilidad a través de las redes de infraestructuras y de las opciones de los agentes para hacerse con los suelos o gestionarlos), las localizaciones más convenientes.

El caso de Eurovegas, un complejo de ocio y juego ${ }^{25}$ promovido por Las Vegas Sands, ejemplifica este urbanismo del papel en blanco, en el que los grandes operadores van modelando el territorio en función de las oportunidades, definiendo -o en este caso, redefiniendo- el destino de los suelos y las determinaciones urbanísticas de acuerdo a cada proyecto ${ }^{26}$.

\footnotetext{
${ }^{25}$ Según el diario El País (9 de Septiembre de 2012), el complejo constará de 12 resorts (9 de 5 estrellas y el resto de 4) con 3.000 habitaciones cada uno (en total 36.000; seis casinos con 1.065 mesas y 18.000 máquinas 'recreativas'; un escenario con 15.000 asientos; 9 salas de espectáculos con 1.800 butacas cada una; 7 teatros con 850 butacas cada uno; 50.000 plazas de restaurantes, bares y discotecas; entre 1 y 3 campos de golf y 40.000 plazas de aparcamiento. La inversión prevista es de 16.900 millones de euros.

${ }^{26}$ Aunque en el momento de redacción de este artículo, aún no se había anunciado oficialmente si el complejo se instalaría finalmente en Alcorcón o en Valdecarros (municipio de Madrid), el caso de los terrenos de Alcorcón ilustra claramente la evolución de su ordenación urbanística de acuerdo a las demandas coyunturales de los operadores.

Originalmente clasificados como no urbanizables, fueron reclasificados en 1999 para albergar una gran operación denominada "Distrito Norte", cuyas características según la web del propio Ayuntamiento son las siguientes: ocupará aproximadamente el $40 \%$ del término municipal, contará con más de 8 millones de metros cuadrados de suelo destinados a fines públicos, lo que supone un $64 \%$ del total. Además, las zonas verdes y la Ciudad Deportiva del Atlético de Madrid ocuparán más de 4,6 millones de metros cuadrados, más de un 36,6\%. La Ciudad Deportiva del Atlético de Madrid tendrá casi 140 ha, que incluirán un estadio para el equipo filial, con una capacidad para alojar 15.000 espectadores; residencia para los jugadores de categorías inferiores y un Centro Médico de alto rendimiento deportivo; diez campos de entrenamiento; Club Social; club de tenis con 16 pistas y otras 26 de padel; dos campos de fútbol de hierba artificial; club de natación con tres vasos; pabellón polideportivo cubierto y un hotel para servicio del club y clientes externos.
} 


\section{Los modelos urbanísticos del Plan General de Madrid: del planeamiento de la austeridad al planeamiento neodesarrollista al "límite de la capacidad"}

\subsection{El Plan General de Madrid de 1985}

El primer plan democrático de la ciudad de Madrid se había gestado hacia 1983, precisamente en el momento más bajo de la crisis demográfica y económica de finales de los 1970 y primeros 1980, y por tanto en un contexto deprimido en el que se había constatado claramente la detención del crecimiento demográfico y la recesión del mercado inmobiliario en el área metropolitana madrileña, de modo que el Plan tomó como premisa este estancamiento — que había sido además especialmente acusado en la capital-, e interpretando que no serían necesarios grandes crecimientos ni nuevas infraestructuras, volvió su mirada hacia la ciudad heredada, apostando por suturar las cicatrices y cerrar las heridas abiertas que habían producido en ella la especulación y el desordenado crecimiento de la etapa desarrollista anterior, convirtiendo el lema "recuperar la ciudad" en el emblema del plan:

El plan que Madrid requiere aparece fundamentalmente como lo que podríamos entender, en términos conceptuales como un "gran Plan de Reforma Interior". Esta es la forma de responder a las necesidades de una ciudad tan consolidada en donde el "cambio" ha de residir mucho más en mejorar las condiciones de vida que en trastocar la configuración física [...], en la reordenación y en el reequipamiento de una ciudad consolidada (Ayuntamiento de Madrid, 1991; citado en De Terán, 1999: 118).

Así, se plantearon una serie de grandes operaciones estructurantes de reforma interior (como la recuperación del río Manzanares o la remodelación de Atocha) y una miríada de pequeñas operaciones de cirugía menor: unas con el objeto de coser los tejidos de la ciudad heredada entre sí o con la periferia, otras para solucionar los bordes urbanos, en coherencia con la idea de rematar la ciudad. De acuerdo a estos

\footnotetext{
Junto a ello, la reserva de suelo para equipamientos públicos ocupará una superficie de suelo de 2,5 millones de metros cuadrados (un $20 \%$ del total). La idea es reservar ese suelo para equipamientos universitarios y de investigación, equipamientos culturales, administrativos e incluso equipamientos deportivos que pudieran formar parte del proyecto olímpico de Madrid. Por su parte, el Distrito Norte incluye más de 3,5 millones de metros para áreas de desarrollo económico y creación de empleo, como parques empresariales o sectores empresariales y terciarios. En lo que se refiere a la vivienda, ésta ocupará un $23 \%$ de la superficie total y permitirá el desarrollo de hasta 18.000 viviendas públicas repartidas al $50 \%$ entre el Ayuntamiento de Alcorcón y la Comunidad de Madrid.

El Tribunal Superior de Justica de Madrid estimó en su sentencia del 11 de mayo de 2012 el recurso contencioso administrativo presentado en 2009 contra la aprobación por parte del gobierno autonómico madrileño de la rectificación para la aprobación definitiva del PGOU de 1999 en la que se incluía el Distrito Norte.
} 
presupuestos, la mayor parte de la capacidad residencial del plan (180.000 viviendas en total $^{27}$ ) se situaba en suelo urbano (122.000 unidades, un 68\%), aunque también se clasificó suelo urbanizable en las operaciones de remate periférico con una capacidad de 56.431 nuevas viviendas.

\subsection{El cambio de coordenadas: la revisión del Plan General de Madrid de 1985 y el Avance de 1990}

No obstante, el panorama recesivo en el cual se había aprobado el Plan General (PG) de Madrid de 1985 cambió súbitamente al hilo del nuevo ciclo de recuperación económica que comenzó ese mismo año, de modo que el Plan hubo de desenvolverse en un contexto muy diferente al de su gestación ${ }^{28}$, sin que hubiese tiempo o voluntad política para rectificarlo. Uno de los efectos más importantes de dicha recuperación económica fue un intenso boom inmobiliario que disparó los precios de la vivienda en Madrid, y del cual se hizo responsable al Plan de 1985, por la supuesta escasez de sus previsiones de viviendas ${ }^{29}$. Resulta chocante que la coalición municipal de izquierdas en el Ayuntamiento cerrase filas rígidamente en defensa del Plan y de su filosofía ante los duros ataques recibidos desde la oposición; mientras el gobierno de la Comunidad de Madrid — que era del mismo color político- rectificaba sin complejos el rumbo de la política territorial hacia 1987, asumiendo claramente el nuevo régimen de acumulación emergente y sus requerimientos espaciales, desterrando definitivamente — como se ha visto- la idea de la austeridad, y sustituyéndola por la visión del territorio como oportunidad, en base a la cual se elaboró la ambiciosa serie de documentos y estrategias territoriales ya comentada.

\footnotetext{
${ }^{27}$ Esta cifra desmiente el argumento del escaso dimensionado de viviendas del Plan de 1985, tantas veces utilizado para responsabilizarle del boom inmobiliario que se produjo tras su aprobación. Teniendo en cuenta que la ciudad de Madrid había perdido unos 170.000 habitantes entre 1975 y 1986 (regresión que, por cierto, continuó otros 10 años más, hasta 1996), las 180.000 nuevas viviendas propuestas por el plan parecen más que razonables.

${ }^{28}$ Lidiando también con algunas medidas sectoriales como el Decreto Boyer sobre la liberalización de los alquileres, que tuvieron un efecto dinamitador sobre el Plan.

${ }^{29}$ En realidad, lo que ocurrió es que el desarrollo de la práctica totalidad del suelo urbanizable previsto en Plan se paralizó como consecuencia de la negativa (y del correspondiente recurso ante los tribunales) de los propietarios de suelo a aceptar las imposiciones realizadas por el PG sobre el porcentaje obligatorio de vivienda protegida. Esto provocó un insólito estancamiento del suelo en Madrid y el incumpliendo flagrante del Programa del Plan, atolladero del cual sólo pudo salirse a través de Convenios ad hoc (denominados de Agilización de Planeamiento) con los propietarios, gracias a los cuales "se liberalizó el tipo de vivienda a realizar en los Planes Parciales, conservándose el aprovechamiento patrimonializable por los propietarios, lo que condujo a que el exceso fuese cedido al Ayuntamiento en forma de suelo para VPO” (Hernández Aja, 2003: 306).
} 
Fue necesario un cambio político en el Ayuntamiento ${ }^{30}$ para que se planteara seria y profundamente la revisión del PG de Madrid, a la luz de las condiciones que se habían manifestado en la segunda mitad de los años 1980 (el "ensayo del nuevo modelo") y que, en la escala metropolitana, habían sido ya asumidas e impulsadas por el gobierno regional. Así pues, el proceso de revisión del PG del 85 vino a significar para Madrid lo que el conjunto de documentos de planeamiento territorial elaborados desde 1987 anticiparon a escala metropolitana: la aceptación de las condiciones "impuestas" por el juego de la competitividad internacional y la asunción del patrón del territorio red como el óptimo para soportar el despliegue espacial del nuevo modelo ${ }^{31}$ de acumulación, recuperando el dibujo de las grandes infraestructuras viarias orbitales e introduciendo nuevos espacios para actividades económicas avanzadas y áreas residenciales.

Aprovechando que el cambio político municipal de 1989 coincidió con el final de la vigencia del primer cuatrienio del Plan, y, por tanto con el momento de revisión de su Programa se comenzó a plantear la revisión completa del Plan. Ese año se creó PROMADRID, cuyo principal objetivo era la realización de un Plan Estratégico de Ciudad, que se presentaría finalmente en 1993. Pero pronto se fue todavía más allá y en 1990 se presentó ya una propuesta en toda regla de Avance de revisión del Plan. Su justificación se basó en que las nuevas propuestas viarias de cierre de la M-30 y de recuperación de la M-40 ${ }^{32}$ planteadas por el MOPU alteraban sustancialmente la estructura dibujada por el PG del 85, así como en la necesidad urgente de encontrar solución al problema de la vivienda desatado tras el boom inmobiliario de finales de los 1980.

El Avance del nuevo plan partía de dos presupuestos muy diferentes a los del PG del 85, que suponían un cambio radical de filosofía con respecto a éste. Por un lado, la constatación del cambio de situación económica y la necesidad de posicionar a la ciudad en el nuevo escenario de la competitividad europea, que se traducía en la reserva de suelo para actividades estratégicas, en línea con el entendimiento del territorio como oportunidad y los documentos de planeamiento territorial impulsados por el gobierno regional socialista. Así, se afirmaba:

Madrid pretende en síntesis, sustentar su posición en el sistema europeo de ciudades sobre la base de la consolidación de un potente conglomerado terciario-industrial,

\footnotetext{
${ }^{30}$ En Mayo de 1989 hubo una Moción de Censura que prosperó, tras una coalición entre PP y CDS, y llevó a la alcaldía a A. Rodríguez Sahagún, del CDS. Finalmente, en las elecciones municipales de 1991, el PP resultó ganador con mayoría absoluta.

${ }^{31}$ Resulta especialmente significativo que ese cambio de rumbo fuese conducido a escala regional por el PSOE y a escala municipal por el centro-derecha, expresando así su coincidencia en las claves principales -que no en los matices- del proyecto hegemónico.

${ }^{32}$ Recogidas en los Convenios entre el MOPU, la Comunidad y el Ayuntamiento de fecha 13 de Febrero de 1986 y, sobre todo, 2 de Diciembre de 1988.
} 
apoyado en un sector financiero fuerte y en una industria innovadora y dinámica. Este objetivo implica fomentar el desarrollo de actividades de servicio estratégicas y de elevada cualificación, promover las actividades industriales en áreas para tecnología avanzada y potenciar las innovaciones en las industrias tradicionales (Ayuntamiento de Madrid, 1992: 51).

Para ello, como en los documentos de planeamiento metropolitano, se proponían una serie de nuevas centralidades, a modo de espacios talismán, que conformarían un nuevo territorio inteligente en la capital: Centro Sur ${ }^{33}$, el Parque Empresarial de los Recintos Feriales, el Área de Actividades Norte de Chamartín (en lo que después sería el PAU de Las Tablas) y la gran operación de reequilibrio regional de la centralidad terciaria en Campamento.

Por otra parte y para resolver el estrangulamiento de la oferta de viviendas, en el Avance se impulsaba también una ambiciosa política de suelo residencial a gran escala, en la que ya se planteaba ocupar prácticamente todo el suelo del término municipal a excepción del Monte del Pardo, reservando nuevo suelo urbanizable para un total de 109.000 viviendas. Entre las nuevas piezas residenciales, se incluían algunas ya planteadas como suelos urbanizables no programados por el PG del 85 (futuros PAUs de Sanchinarro, Montecarmelo y Arroyo del Fresno), en las que se multiplicaba el número de viviendas original; al tiempo que se introducían otras nuevos desarrollos sobre suelos no urbanizables ${ }^{34}$ del 85 , entre los que destacaba la Estrategia del Sureste Metropolitano, con una superficie de 3.500 ha y 70.000 viviendas ${ }^{35}$.

Tras la victoria electoral municipal del PP en 1991, se acometió en firme la propuesta de Revisión del PG; y en Enero de 1992 ya se constituyó la nueva Oficina Municipal del Plan de Madrid (OMP).

Sin embargo, en 1992 se desató una breve pero intensa crisis económica que, como se ha comentado, produjo un súbito estancamiento de la demanda de espacio

\footnotetext{
${ }^{33}$ Convirtiendo la tímida apuesta del PG del 85 por el sur (que se había limitado a mantener el uso industrial -ya obsoleto- y al PERI Estación Sur, con $65.500 \mathrm{~m}^{2}$ de oficinas y $34.500 \mathrm{~m}^{2}$ comerciales) en un ambicioso proyecto de reequilibrio norte sur que englobaba Arganzuela, Méndez Álvaro, el Abroñigal y Las Carolinas, con 380 ha y $1.200 .0000 \mathrm{de}^{2}$ terciarios.

${ }^{34}$ Finalmente, en el PG de 1997 se reclasificaron 28 sectores (entre ellos la mayor parte de los PAUs y toda la Estrategia del Este), que eran suelo no urbanizable especialmente protegido en el PG de 1985. Años después, las sentencias del Tribunal Superior de Justicia de Madrid de 27 de Febrero de 2003 y de 31 de Enero de 2008 y del Tribunal Supremo de 3 de Julio de 2007 han considerado injustificadas esas reclasificaciones, obligando a las administraciones competentes a "justificar la reclasificación de terrenos no urbanizables protegidos", cuando ya están edificadas la mayor parte de las viviendas. De este modo -invirtiendo toda racionalidad - la justificación de los desarrollos, que debería haber sido previa a éstos, se producirá sobre los hechos consumados.

${ }^{35}$ La gigantesca Estrategia del Este finalmente se incluiría dentro del Plan General de 1997, aumentado su superficie a $4.978,8$ ha y sus viviendas a 122.613 .
} 
para actividades económicas y del mercado inmobiliario residencial madrileño. De este modo, el contexto de la primera mitad de los años 1990 fue nuevamente recesivo, lo cual se tradujo en una paralización del planeamiento en toda la Comunidad de Madrid.

La revisión del mismísimo Plan General de Madrid, que como hemos visto había comenzado con una urgencia desaforada en 1990, se dilató hasta 1997, año en que se aprobó definitivamente el documento del Nuevo Plan General (NPG). Como ocurriera con el anterior, este Plan General de Madrid de 1997 también sería representativo de una nueva generación de planes madrileños, nacidos en torno al cambio de siglo.

\subsection{El PG de Madrid de 1997 como modelo de planeamiento neodesarrollista "al limite de la capacidad"}

Desde el punto de vista conceptual confluyen en el Plan de 1997 toda una serie de ideas que se convertirían en tópicos del planeamiento neodesarrollista finisecular. En primer lugar, poco a poco - y en paralelo al incremento de los precios en la fase final del boom - fue tomando fuerza el argumento de la vivienda, sustituyendo en el discurso político al de la competitividad internacional — también en paralelo al súbito agotamiento hacia 1992 del modelo de crecimiento español de finales de los 1980-; fruto de lo cual se abandonó el discurso iluminista del "territorio inteligente" que había entendido éste como campo de "oportunidades" para el despliegue de las nuevas actividades avanzadas que contribuyeran a la competitividad internacional; dejando paso a un proyecto mucho más "doméstico" e inmediato - por no decir pacato- en el que por "oportunidades" del territorio se pasaba a entender la existencia de huecos que permitieran su relleno con viviendas, en especial los suelos puestos en carga por las infraestructuras o los alvéolos atrapados por éstas.

Así se explicitaba en el epígrafe expresivamente titulado "De los límites impuestos a las oportunidades del territorio" del documento de la Aprobación Inicial de 1995, donde se decía:

[L]a construcción de la M-40 dejaba sin sentido al modelo territorial del Plan General del 85, y permitía el acceso a nuevas áreas, colindantes con la ciudad, y que en ese Plan aparecen como huecos. Utilizar esos huecos para aliviar las presiones de la ciudad, ofreciéndole el suelo que necesita, los convierte en oportunidades para el desarrollo [...]. Otros huecos de suelos obsoletos o de áreas degradadas en la ciudad actual, permitirán mejorar las periferias actuales y preparar la transición a los nuevos desarrollos [...] De este modo se ponen los "suelos muertos" al servicio del desarrollo de las oportunidades que Madrid requiere (Ayuntamiento de Madrid, 1995: 10). 
Figura 2a. Plano de clasificación del suelo del PG de Madrid de 1985

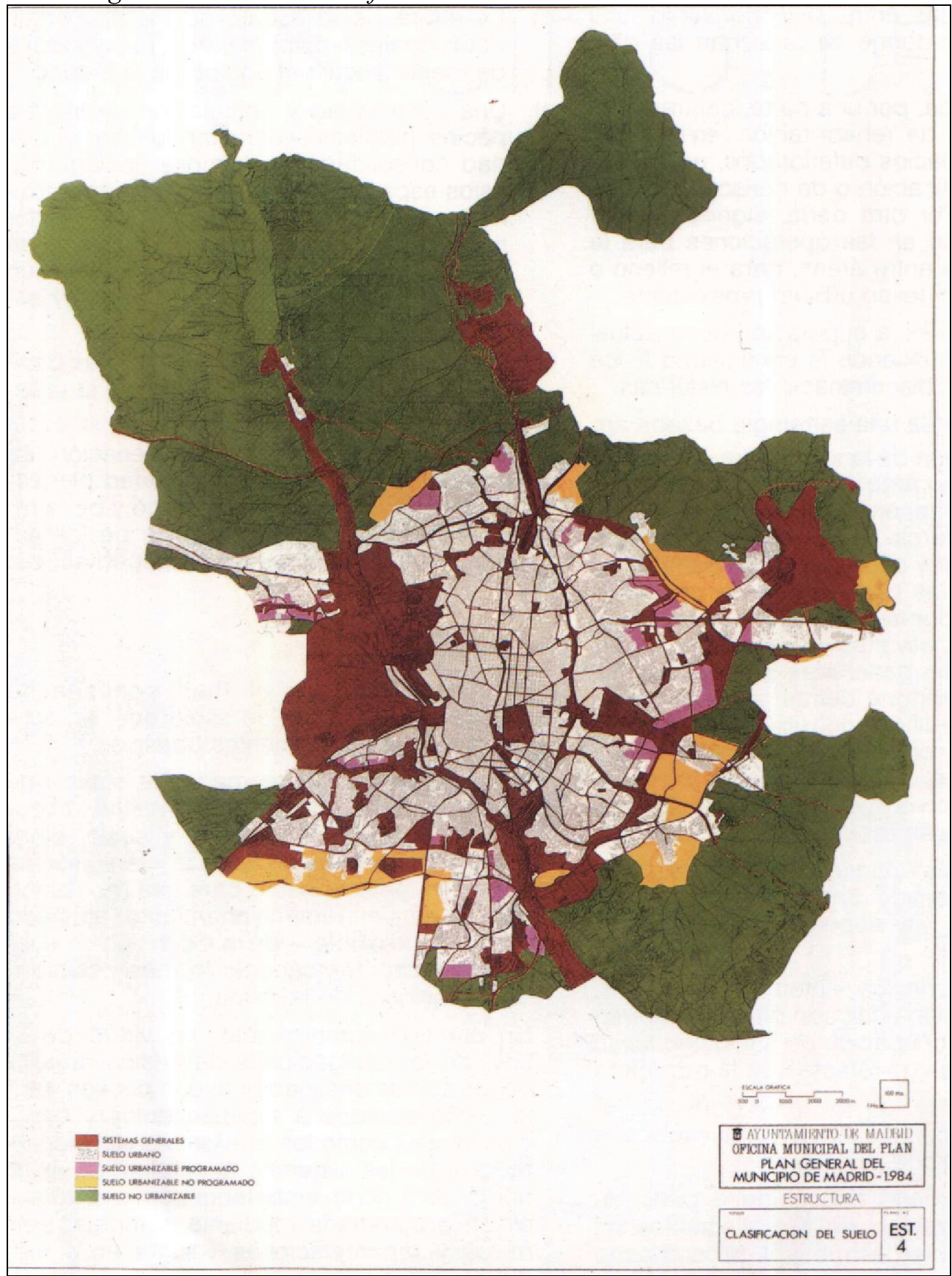

Fuente: Ayuntamiento de Madrid (1985). Plan General de Ordenación Urbana de Madrid. 
Figura 2b. Plano de clasificación del suelo del PG de Madrid de 1997

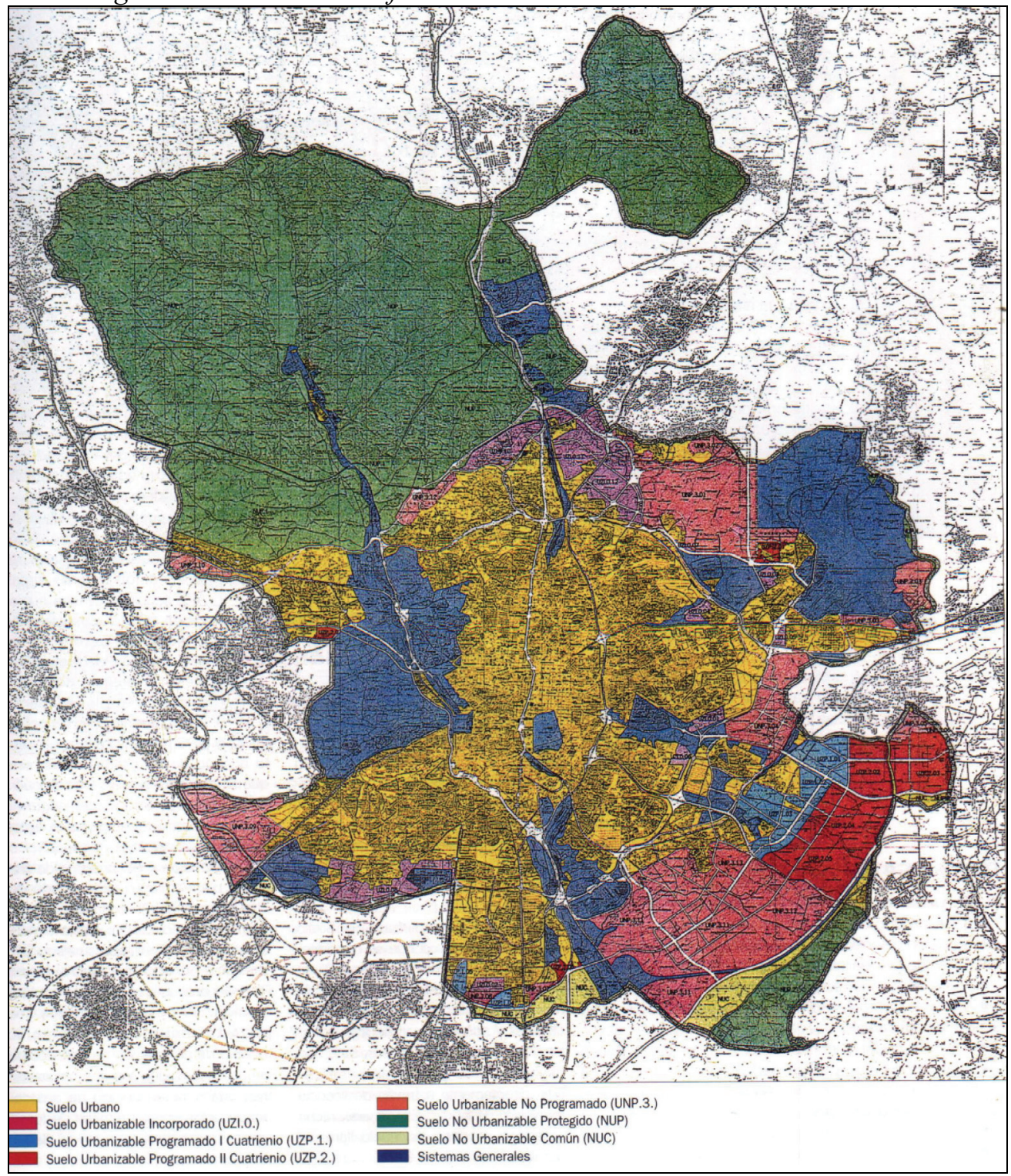

Fuente: Ayuntamiento de Madrid (1997). Plan General de Ordenación Urbana de Madrid.

De este modo, los reclamos de liberalización del suelo y de la conveniencia de la sobreclasificación para disminuir los precios de la vivienda - que, como hemos visto se repetían como mantras hipnóticos por aquellos años y que se terminarían incorporando a la legislación autonómica del suelo en 2001- iban a encontrar en 
los "huecos" del territorio la posibilidad de rellenarlos con viviendas, alumbrando lo que sería el lema del Plan de 1997: el "planeamiento al límite de la capacidad", asumiendo la identificación pura y dura del territorio con el suelo (urbanizable).

De modo que de aquellas bienintencionadas apuestas por la creación de "territorios inteligentes" que aún persistían en el Avance de 1990, no quedó prácticamente nada $^{36}$ en la redacción del NPG: desapareció el carácter de centralidad de la operación Centro Sur, convertida en un monocultivo residencial para las clases medias; desapareció el Parque Empresarial de los Recintos Feriales; el Área de Nuevas Actividades Norte de Chamartín se transformó en el PAU de Las Tablas; la operación Campamento vio diluirse su carácter de "difusión de la centralidad"; mientras la Estrategia del Este y los nuevos ensanches perdieron la mayor parte de la edificabilidad terciaria o de otros usos que se había previsto en el Avance de 1990, convirtiéndose en barrios dormitorio con centro comercial incorporado. Todo quedó en entender los suelos vacíos como suelos muertos, que había que poner en juego; como huecos que había que rellenar. Y se programó ese relleno del suelo hasta su agotamiento en dos fases: en la primera, el interior de la M-40, y en la segunda, el espacio entre ésta y la M-50.

El Plan General de Madrid de 1997 planteó en la práctica la urbanización de todo el suelo vacante del municipio (con excepción del Monte del Pardo), con una capacidad para casi 356.000 nuevas viviendas ${ }^{37}$, clasificando como urbano 16.456 ha, 4.487 ha como urbanizables y 16.688 ha como Sistemas Generales (SG), de modo que el suelo total de ocupación prevista era un total de 37.612 ha, siendo el suelo no urbanizable restante (común y protegido) 22.855 ha. Respecto al PG de 1985, esto suponía incrementar 2.615 ha el suelo urbano $(+18,9 \%), 1.393$ ha el suelo urbanizable $(+45 \%)$, y 6.099 ha los SG $(+57,7 \%)$; es decir, un total de 10.108 ha de suelo ocupado más $(+36,7 \%)$, a expensas de una simétrica reducción del suelo no urbanizable, que pasaba de ser un $54,7 \%$ del total del municipio a un $37,8 \%$, la mayoría del cual era suelo protegido (21.324 ha, correspondientes en su mayor parte a las bolsas intocables del Monte del Pardo y el Soto de Viñuelas), reducción,

\footnotetext{
${ }^{36}$ Las operaciones estructurantes finalmente propuestas por el NPG fueron 8. Cuatro en suelo urbano (la Transformación del Sur, la Recuperación de la Avenida de Córdoba, la Ordenación del Casco de Vicálvaro, y la Prolongación de la Castellana), y cuatro en suelo urbanizable (Ampliación de Barajas-Ciudad Aeroportuaria-Parque de Valdebebas, Nueva Centralidad del Este, Remate del Suroeste y Estrategia del Este). De ellas sólo las operaciones de la Castellana y Barajas pueden considerarse como propiamente de centralidad, con un porcentaje significativo de usos terciarios. La primera rectifica el intento de "dar salida" a la centralidad por el Sur, conduciendo ésta hacia su "lugar natural", mientras la Operación Barajas-Valdebebas, a través de las sucesivas modificaciones posteriores a la aprobación del NPG se ha descafeinado como centralidad y como parque, para convertirse casi exclusivamente en otro ensanche residencial más. La nueva Centralidad del Este era la única planteada como tal, aunque su destino actual es incierto después de los olímpicos descalabros de M-2012 y M-2016.

${ }^{37}$ Aproximadamente la mitad en suelo urbano y la mitad en urbanizable.
} 
por lo tanto, a costa del suelo no urbanizable común, que quedaba reducido a 1.529 ha testimoniales (apenas un 2,5\% del total municipal, y en localización absolutamente residual).

Como puede verse, se trata de un Plan con elevado consumo de suelo, fiel exponente de las ideas de agotamiento al máximo de la capacidad municipal y de satisfacción de los reclamos de incremento de la oferta de suelo a través de la liberalización y de la clasificación masiva de éste, que dibuja el crecimiento máximo del municipio, comprometiendo todo el suelo posible y cerrando su vocación, aun sin determinar un plazo temporal para su colmatación.

Paradójicamente, el Plan General de Madrid de 1997 ejemplifica también cómo la voluntad expansionista municipal y el modelo neodesarrollista de "planeamiento al límite de la capacidad" han podido prevaler incluso por encima de la legislación urbanística, pues el Plan fue redactado en base a la "hiperortodoxa" Ley estatal de 1990, demostrando los amplios márgenes de ésta y la falta de necesidad de las reformas liberalizadoras en la escala estatal (1998 y 2000) y autonómica (2001).

\subsection{Las novedades metodológicas del PG de Madrid de 1997}

El otro aspecto en el que el Plan de Madrid de 1997 resultó también representativo de su generación, fue el metodológico. Sin entrar a describir el complejo culebrón ${ }^{38}$ de los Programas de Actuación Urbanística (PAUs), lo que nos interesa destacar aquí es cómo en base a la supuesta urgencia del problema de la vivienda en Madrid -con el fin de que el suelo estuviera disponible en el mercado durante el primer Cuatrimestre de vigencia del NPG-, la opción para su desarrollo fue la tramitación sector a sector de las respectivas Modificaciones Puntuales del Plan General (MPG) de 1985, de forma simultánea a su incorporación al NPG que se estaba redactando al mismo tiempo. Este singular procedimiento de doble tramitación paralela significaba en realidad, como indica Leguina (2004: 74), dar a los PAUs una cobertura legal suplementaria que permitiera llevar adelante la operación, aun en el caso en que se empantanase el procedimiento de las MPG.

Más allá de la inconveniencia de las MPG, que encubrían claramente una revisión completa del PG de 1985 - que se iba tramitando descaradamente de forma paralela-, el flujo de modificaciones remitidas desde la Gerencia Municipal de Urbanismo (GMU) a la Oficina Municipal del Plan (OMP) producía la aberración de estar armando un plan general en el que lo primero era el planeamiento de desa-

\footnotetext{
${ }^{38}$ Desarrollado en De Santiago (2005, 2007).
} 
rrollo $^{39}$ y la ordenación pormenorizada de los sectores de suelo urbanizable, limitándose el PG a darles una "coherencia" a posteriori.

Pero el recurso puro y duro a la utilización discrecional de las Modificaciones Puntuales del Plan General (MPG) para moldear el planeamiento de acuerdo a las oportunidades coyunturales o particulares, obviando el proceso - mucho más complejo y dilatado - de una revisión completa del planeamiento en toda regla, también ha tenido otro ejemplo paradigmático en la ciudad de Madrid: la doble carambola de las operaciones de la Ciudad Deportiva del Real Madrid y de Valdebebas.

En general - y no sólo en Madrid—, esta proliferación de MPG se relaciona íntimamente con un modelo de planificación urbanística "a la carta" y "a golpe de convenio" en la que son "los intereses privados, de propietarios o de empresas promotoras, los que están marcando la transformación del territorio" (Burriel de Orueta, 2008), pues buena parte de

las enormes actuaciones urbanísticas de estos años han sido presentadas por empresas privadas y aprobadas con rapidez por los ayuntamientos sin que éstos se hubieran planteado previamente el desarrollo urbanístico de esa zona o en esas formas, plazos o intensidad. De este modo, son los intereses de las empresas los que están determinando los procesos de transformación del territorio e incluso, cada vez con más frecuencia, están decidiendo el contenido mismo de los nuevos planes urbanísticos (Burriel de Orueta, 2008).

Como quiera que en la actualidad, el planeamiento urbanístico está formulado legalmente en términos que impedirían o - cuando menos- exigirían una mayor reflexión y consenso público para estas operaciones sobrevenidas, coyunturales o "a la carta", se han buscado para ellas todo tipo de atajos y de instrumentos excepcionales en los márgenes de la legalidad que permiten al mismo tiempo simplificarlas y darles una apariencia formal y legalmente impecable. Los instrumentos más habituales para desarrollar este tipo de operaciones han sido las MPG y los convenios urbanísticos entre la Administración y los agentes privados, sobre todo para dar cobertura legal y poder llevar a cabo con agilidad generosas reclasificaciones o recalificaciones de suelo que desde el punto de vista ortodoxo hubiesen requerido engorrosas revisiones del planeamiento. Mediante este procedimiento, el pastel se ha repartido "civilizada y cuidadosamente" para que las partes puedan quedar satisfechas: así, no sólo los privados han obtenido millonarias plusvalías en las reclasificaciones, sino que los mismos ayuntamientos han sabido "sacar su tajada",

\footnotetext{
${ }^{39}$ En algunos casos, la inversión iba aún más lejos: el punto de partida era la definición de las infraestructuras - y de las cargas asociadas a ellas-, que condicionaba el aprovechamiento, en base al cual se definía la viabilidad económica de las operaciones, que era el criterio fundamental para su diseño y planificación.
} 
al exigir un precio - determinadas contraprestaciones en dinero, aprovechamiento, infraestructuras, etc. - para "vender" esa "potestad pública urbanística" (Burriel de Orueta, 2008) que no hay que olvidar que ejercen sólo en representación de los ciudadanos, precisamente los únicos no consultados en todo el proceso. Aunque recientemente se ha intentado detener esta aberrante deriva hacia el "urbanismo del chalaneo" ${ }^{40}$, lo que quizá ya sea irreversible es la devaluación del planeamiento como instrumento regulador, al haberse convertido en una mera herramienta administrativa que simplemente da cobertura formal a operaciones que pueden ser legal y formalmente intachables, pero que ética y urbanísticamente son - cuando menos- bastante cuestionables.

La operación de la Ciudad Deportiva del Real Madrid ${ }^{41}$ se justificó en base dos premisas: la Operación Chamartín y los Juegos Olímpicos. En el Convenio a tres bandas $^{42}$ de fecha 7 de Mayo de 2001, firmado entre el Ayuntamiento, el Real Madrid CF, y la Comunidad de Madrid, se explicaba que su privilegiada situación en la ciudad convertía "en estratégica su futura incorporación, funcional e infraestructural al nuevo crecimiento estructurante de Madrid en la Corona Norte Metropolitana" que significaba el proyecto de "Prolongación de la Castellana", mientras, por otro lado, se destacaba "el alto valor estratégico del suelo objeto de este Convenio destinado a la construcción de un Pabellón de Madrid [...] con la incorporación de instalaciones de Alta Competición, acompañado de una importante reserva de suelo público para espacios libres, zonas verdes y espacio para aparcamiento y, en su caso, intercambiador de transporte" (Apartado IV del Convenio). Tomando como base estas premisas, las Administraciones implicadas se comprometían a modificar el Plan General en el ámbito de las $15,06 \mathrm{ha}^{43}$ de la Ciudad Deportiva del Real Madrid, y a elaborar un APR, estableciendo un aprovechamiento de $1,49 \mathrm{~m}^{2} / \mathrm{m}^{2}$, lo que suponía una edificabilidad terciaria de $225.000 \mathrm{~m}^{2}$ distribuida en 4 torres, que se repartiría asignando aproximadamente la edificabilidad de una torre al Ayuntamiento, media a la Comunidad y dos y media al Real Madrid. Además se comprometían a "tramitar la modificación de planeamiento y facilitar cuantas gestiones sean

\footnotetext{
${ }^{40}$ Ante la inquietud social suscitada por determinados escándalos se ha intentado reconducirlo: así, la Ley estatal 8/2007 obligó a someter a los convenios al trámite de información pública, y en Madrid se suprimieron los convenios de planeamiento mediante la Ley 3/2007. Conviene recordar también los numerosos casos de corrupción urbanística.

${ }^{41}$ Sobre esta operación, véase también Arias (2009).

${ }^{42}$ Como se indicaba muy expresivamente en la prensa "el Alcalde tiene la máquina de hacer billetes en su capacidad de recalificar el terreno de equipamiento deportivo a terciario, y [Florentino] Pérez, la propiedad del suelo sobre el que se puede hacer el milagro. La Comunidad de Madrid [...] cuenta con la potestad última de aprobar la operación". (El País, 9 de Febrero de 2001).

${ }^{43}$ La parcela original de la Ciudad Deportiva la había comprado el Real Madrid a la Comisaría de Ordenación Urbana en 1960, y tenía una superficie de $140.627 \mathrm{~m}^{2}$, de la cual se había segregado una parte de $30.000 \mathrm{~m}^{2}$ para vendérsela a la Comunidad y al Ayuntamiento en 1999. Además, el Ayuntamiento aportaba también $10.050 \mathrm{~m}^{2}$ de una zona verde aneja.
} 
necesarias [...] para la implantación de una nueva «Ciudad Deportiva» del Real Madrid Club de Fútbol en el ámbito del UNP 4.01 «Ciudad Aeroportuaria y Parque de Valdebebas», en una parcela calificada como dotacional deportivo de 120 ha" (Apartado IV del Convenio). La Modificación del Plan General se produjo finalmente el 4 de Diciembre de 2001, y las 4 torres se construyeron entre 2004 y 2008. Mientras, el pabellón de Alta Competición para los JJ OO - que fue una de las justificaciones básicas de la operación ${ }^{44}$ - se sustituyó mediante otra MPG por un Centro Internacional de Convenciones - al tiempo que se casi se doblaba su edificabilidad $^{45}$ - y a fecha de 2012 se desconoce todavía si algún día se construirá.

En cuanto a la segunda parte de esta doble carambola inmobiliaria, el 27 de Julio de 2002 se aprobó inicialmente la Modificación del Plan General y el avance del Plan de Sectorización UNP 4.01 Ciudad Aeroportuaria-Parque de Valdebebas, dando forma al Convenio de planeamiento establecido entre la Comunidad, el Ayuntamiento y el Real Madrid de fecha 16 de Julio de 2002 y al Convenio de gestión suscrito el día siguiente entre Ayuntamiento, Real Madrid y los propietarios de suelo. En Julio de 2004, la Comunidad adoptó el acuerdo de instalar la Ciudad de la Justicia en Valdebebas, y en Diciembre de 2004 se aprobó definitivamente el Plan Parcial.

Estas operaciones ilustran cómo la visión global y unitaria de la ciudad, que constituía el núcleo central del planeamiento urbanístico, se ha visto sustituida por la suma o yuxtaposición de proyectos fragmentarios sobrevenidos fuera del Plan y del Programa, casi siempre con carácter emblemático y oportunista, pero con una influencia y una repercusión sobre la estructura urbana de la ciudad infinitamente mayor que la de otras actuaciones — supuestamente estructurantes- recogidas por los propios planes. El ejemplo más claro de este tipo de operaciones sería el reciente soterramiento de la M-30, que redefiniendo completamente la estructura de movilidad urbana y metropolitana, deriva de una idea "más o menos feliz" posterior al NPG, mientras que otras recogidas rimbombantemente como operaciones estructurantes en el planeamiento - caso de la Recuperación de la Avenida de Córdobase relegaron o se convirtieron en operaciones sin ninguna trascendencia urbana. El viejo debate entre plan y proyecto se cerraría así de modo pragmático, cercano al de la Planificación Estratégica: la ciudad se proyecta según el pulso de las oportunidades, y se recompone la idea de conjunto mediante un simple documento que yuxtapone las operaciones ortodoxas y las sobrevenidas, como ejemplifica el Plano del Programa Operativo de Urbanismo, Vivienda e Infraestructuras 2004-2007 del Ayuntamiento de Madrid. Según se afirma en la Memoria de Gestión de 2006, "desde el punto de vista técnico, el Programa Operativo es una herramienta de

\footnotetext{
${ }^{44}$ La otra, la Operación Chamartín, está también estancada.

${ }^{45}$ De $40.000 \mathrm{~m}^{2}$ a $70.000 \mathrm{~m}^{2}$.
} 
gestión estratégica en la que se traducen los compromisos electorales que el actual equipo de gobierno ha asumido con los ciudadanos - en materia de urbanismo, vivienda e infraestructuras - en un conjunto integrado de acciones" (Ayuntamiento de Madrid, 2006: 27). De este modo, del Plan como síntesis del modelo de ciudad, se pasaría al "conjunto integrado de acciones".

Por otra parte, se sugiere también la búsqueda de nuevas herramientas urbanísticas que sustituyan o releven al planeamiento tradicional, pues una vez diseñado el crecimiento máximo de la ciudad en el PG de 1997, cerrado por tanto su modelo de ocupación de suelo y concluida la tarea fundamental (la clasificación del suelo) del plan general clásico tal y como fue formulado en su momento (exclusivamente para "ordenar" el crecimiento), la ciudad precisaría dotarse de un nuevo instrumento -abierto y cerrado al mismo tiempo-, capaz de gestionar la transformación permanente de una ciudad que ya no puede crecer más. Abierto como "un instrumento vivo, que debe adquirir valor y evolucionar con el tiempo, lo que permite incluir en él nuevas acciones o reformular las ya planteadas. Todo ello para dar respuesta a nuevas circunstancias o diferentes situaciones que no pudieron ser previstas inicialmente" (ibídem), pero cerrado en cuanto a que las cuestiones en él contempladas (la definición del modelo de ciudad, la revitalización del centro, las actuaciones olímpicas, la transformación de la M-30, o el estudio de nuevas operaciones estructurantes como el Abroñigal o los Parques Tecnológicos) se debatirían sólo internamente, sin una mínima participación ciudadana directa y reglada.

Finalmente, en su programa de gobierno 2011-2015, el Ayuntamiento de Madrid ha terminado planteando una revisión formal del PG de 1997, creando una Dirección General para llevarla a cabo, dependiente de la Oficina de Planificación Urbana y responsable de la redacción del nuevo Plan General ${ }^{46}$.

\section{Conclusiones}

Los datos del boom inmobiliario de la última década desmienten los argumentos mercantilistas que se barajaron para liberalizar el suelo o, al menos, su eficacia. En efecto, durante el boom inmobiliario 1997-2007 han coincidido, contradiciendo la idea clásica de equilibrio entre oferta y demanda $-\mathrm{y}$ la prometida bajada de los precios con el incremento de la oferta-, un incremento espectacular de la oferta de suelo y de la producción de viviendas - pues la máquina inmobiliaria madrileña fue capaz de clasificar suelo para más de 625.000 viviendas, y de construir volúmenes

\footnotetext{
46 Véase URL: > http://www.madrid.es/portales/munimadrid/es/Inicio/Ayuntamiento/Urbanismo-eInfraestructuras/Revision-del-Plan-General/Presentacion?vgnextfmt=default\&vgnextchannel $=663 \mathrm{~b} 3 \mathrm{a} 70 \mathrm{~b} 7974310$ VgnVCM1000000b205a0aRCRD $>$. Consultado el 9 de Septiembre de 2012.
} 
anuales de vivienda que alcanzaron casi las 78.000 en 2004-, con un incremento igualmente espectacular de los precios. Así, desde 1998 (año de la primera liberalización, mediante la Ley 6/1998) hasta 2007, el precio medio de la vivienda libre en la Comunidad de Madrid ha crecido un 182,4\%, y desde 2001 (año de la segunda vuelta liberalizadora de la Ley autonómica 9/2001) un 109,7\%. Es más, desde que se tienen datos homogéneos de precios de vivienda y suelo (2004) hasta la actualidad, los incrementos de ambos han sido sensiblemente paralelos (en torno al 24\%).

Como consecuencia de esta oferta sobreabundante, y tras el estallido de la burbuja, en la actualidad nos encontramos en plena resaca inmobiliaria, incapaces de deglutir el suelo clasificado vacante, suficiente para construir todavía más de 525.000 viviendas, mientras permanecen vacías 50.000 viviendas sin estrenar, además de las que correspondan de las 306.000 categorizadas como viviendas vacías según el Censo de $2001^{47}$.

Quizá haya sido necesario recorrer ese largo camino, artificializar más de 30.000 ha entre 1987 y 2000, construir 566.000 viviendas entre 1997 y 2007, aprobar varias leyes y varias modificaciones, para que Enrique Porto Rey, entonces director General de Urbanismo de la Comunidad de Madrid $^{48}$, llegase a reconocer en 2005 que "el planeamiento ha sido capaz de ir por delante del mercado de vivienda" (2005: 12) y que "los posibles estrangulamientos no se derivan de la falta de suelo y, por tanto de la necesidad de calificar de forma masiva nuevo suelo" (2005: 32), confesando implícitamente así la inoperatividad de la liberalización.

En el caso del Ayuntamiento de Madrid, el reconocimiento del fracaso de la liberalización del suelo y del planeamiento al límite de la capacidad es aún más explícito. En el documento de análisis y evaluación del Plan General de 1997, elaborado con motivo de la redacción del Avance del nuevo Plan General, se confirma (Ayuntamiento de Madrid, 2012: 127) el paralelismo en la evolución del precio de la vivienda en España y el municipio de Madrid durante el boom inmobiliario. De forma aún más clara se reconoce ${ }^{49}$ :

[L]a participación del capital suelo en el capital vivienda no ha dejado de crecer [en Madrid] desde finales de la década de los 90. A principios de los 90, la participación del suelo en la vivienda no alcanzaba el 30\% y en 2008 esta participación era superior al 45\%. Es decir, que entre 1990 y 2008 el valor del suelo se ha multiplicado [en el municipio de Madrid] por ocho mientras que el de la edificación lo ha hecho

\footnotetext{
${ }^{47}$ Datos del Sistema de Información Urbana y del Estudio sobre el stock de viviendas nuevas a 31 de diciembre. Ministerio de Fomento.

${ }^{48}$ Dimitió en 2006, "para defenderse con libertad" de las sospechas aireadas por la prensa sobre su actividad privada en ciertas operaciones urbanísticas.

${ }^{49}$ Esto es especialmente ilustrativo, pues implica reconocer el fracaso del argumento central de todo el discurso de la "flexibilización de la actividad urbanística" emprendida desde los años 1990: que la vivienda era cara porque lo era el suelo, y que el precio de éste se fijaba según las leyes convencionales del mercado.
} 
tan sólo por tres. Además, estos incrementos se concentran básicamente en la última década de la serie 1997-2007, en la que el precio del suelo crece a una media del $25 \%$ anual. Este tipo de comportamiento en los precios de la vivienda y el suelo era precisamente el que se proponía evitar el Plan General de 1997 cuando planteaba como meta facilitar el acceso a la vivienda a los ciudadanos demandantes generando suelo urbanizado suficiente para estabilizar los precios (Ayuntamiento de Madrid, 2012: 127).

Finalmente se reconoce también que "el planeamiento al límite de la capacidad territorial del municipio no constituye por sí mismo un factor de estabilización del mercado inmobiliario residencial y por el contrario sí plantea un modelo de desarrollo urbano extremadamente caro en términos de generación y mantenimiento de las redes públicas de infraestructuras implicadas" (Ayuntamiento de Madrid, 2012: 129) o que "al llevar el planeamiento al límite de la capacidad de acogida del término municipal, pero sin considerar los límites ambientales, sociales y económicos del modelo, se consolida un proceso expansivo con un gran consumo de suelo" (Ayuntamiento de Madrid, 2012: 51).

Pero el precio pagado y por pagar para terminar reencontrando la senda de la racionalidad parece muy elevado: una ocupación del suelo desmedida que ya es irreversible, la explosión urbana dispersiva asociada a un modelo de movilidad insostenible y de difícil reconducción, la fragmentación territorial y la segregación de los usos, el acoso de los espacios naturales más valiosos, la intensificación del consumo de recursos materiales y energéticos, la crisis de parte del sistema financiero (BANKIA) por su exposición al sector inmobiliario, etc.; a los que se suman la presión del yugo hipotecario que sufren muchos ciudadanos y las dificultades de otros para encontrar una vivienda digna en medio de esta bulimia inmobiliaria.

Ojalá no sea ya demasiado tarde para rectificar el rumbo.

\section{Bibliografía}

Acierno, Antonio, y, Mazza Angelino (2008) Città in trasformazione. L'esplosione urbana di Madrid. Roma: Aracne Editrice (collana Studi urbanistici).

Aguilera, Federico, y Naredo, José Manuel (eds.) (2009) Economía, poder y megaproyectos. Lanzarote: Ed. Fundación César Manrique.

Arias, Félix (2009) "Megaproyectos urbanos madrileños. ¿Quién manda en Madrid?. Las cuatro torres y el señor de los anillos", en F. Aguilera y J. M. Naredo (eds.) Economía, Poder y Megaproyectos. Lanzarote: Ed. Fundación César Manrique, 181-208.

Ayuntamiento de Madrid (1992) Revisión del Plan General de Ordenación Urbana de Madrid. Fase de Avance. Madrid: Ayuntamiento de Madrid. 
Ayuntamiento de Madrid (1995) Madrid despega hacia el siglo XXI: NPG Nuevo Plan General. Aprobación Inicial. Madrid: Ayuntamiento de Madrid.

Ayuntamiento de Madrid. Área de Gobierno de Urbanismo, Vivienda e Infraestructuras (2006) Memoria de Gestión 2006. Madrid: Ayuntamiento de Madrid [URL: $<$ http://www.madrid.es/UnidadWeb/Contenidos/Publicaciones/TemaUrbanismo/ MemoriaDeGestion2006/MemoriaGMU2006.pdf>. Consultado el 12 de octubre de 2012].

Ayuntamiento de Madrid (2012) Revisión del Plan General. Evaluación del Plan General de 1997. Madrid: Ayuntamiento de Madrid (Dirección General de Revisión del Plan General) [Puesto en línea el 22 de mayo de 2012. URL: $<$ http://www.madrid.es/UnidadWeb/Contenidos/Navegaciones/PGOU/Legislaci on/EVALUACION_PG97_may12.pdf $>$. Consultado el 13 de Junio de 2012].

Burriel de Orueta, Eugenio L. (2008) "La «década prodigiosa» del urbanismo español (1997-2006)". Diez años de cambios en el Mundo, en la Geografía y en las Ciencias Sociales, 1999-2008, Actas del X Coloquio Internacional de Geocrítica, Universidad de Barcelona, 26-30 de mayo de 2008 [URL: $<$ http://www.ub.edu/geocrit/sn/sn-270/sn-270-64.htm>. Consultado 12 de octubre de 2012].

De Santiago Rodríguez, Eduardo (2005) Nuevas formas y procesos espaciales en la región urbana de Madrid: las lógicas del espacio en la construcción de la "ciudad única". Tesis Doctoral, ETSAM, Universidad Politécnica de Madrid. [URL: $<$ http://www.aq.upm.es/Departamentos/Urbanismo/doctorado/tleida17.html>. Consultado el 10 de Enero de 2012].

De Santiago Rodríguez, Eduardo (2007) "Madrid, «ciudad única». Pautas y lógicas espaciales recientes en la región madrileña". URBAN, $\mathrm{n}^{\circ} .12,8-33$.

De Terán, Fernando (1999) Madrid: Ciudad región. Entre la ciudad y el territorio, en la segunda mitad del siglo XX. Madrid: COPUT, Comunidad de Madrid.

Director General de Urbanismo y Planificación Regional (2005) Perspectivas demográficas, urbanisticas y económicas de la Comunidad de Madrid. [URL: $<$ http://www.eurometrex.org/Docs/Moscow/Madrid_economy_ES.pdf $>$. Consultado el 26 de Enero de 2012].

Fernández Durán, Ramón (2006) El Tsunami Urbanizador Español y Mundial. Barcelona: Virus.

Gago, Jesús (2005) "Informe conclusivo. Resumen. Asesoramiento a la Junta de Gobierno del COAM en el proceso de reforma de la legislación urbanística de la Comunidad de Madrid". [URL: $<$ http://www.coam.org/pls/portal/docs/PAGE/COAM/COAM_AYUDA_PROFE SIONAL/HTML/CAT12210.html>. Consultado el 30 de Junio de 2012].

García Montalvo, José (2004) "La vivienda en España: desgravaciones, burbujas y otras historias". Perspectivas del sistema financiero, $\mathrm{n}^{\circ} .78,1-43$. 
García Bellido, Javier (1993) "La liberalización efectiva del mercado del suelo: escisión del viejo derecho de propiedad inmobiliaria en una sociedad avanzada". Ciudad y Territorio: Estudios territoriales, $\mathrm{n}^{\circ}$ 95-96, 175-198.

González García, Isabel, y Hernández Aja, Agustín (2008) "El significado urbanístico de la legislación del suelo: hacia un nuevo modelo urbano y una nueva visión del planeamiento", en A. Acierno y A. Mazza (eds.) Città in transformazione. L'esplosione urbana di Madrid. Roma: Aracne Editrice.

Hernández Aja, Agustín (2003) "El Plan 18.000”, en AA VV Un siglo de vivienda social 1903-2003. Madrid: Editorial Nerea, 305-307.

Leguina, Joaquín (2004) "Que veinte años no es nada", en J. Borja y Z. Muxí (eds.) Urbanismo en el siglo XXI: Una visión crítica. Bilbao, Madrid, Valencia, Barcelona. Barcelona: Edicions UPC, 65-77.

López de Lucio, Ramón (2003) "Transformaciones territoriales recientes en la región urbana de Madrid". URBAN, $\mathrm{n}^{\circ} .8,124-161$.

Menéndez Rexach, Ángel (2006) “Los objetivos económicos de la regulación del suelo: evolución de la legislación española y perspectivas de reforma". Papeles de Economía Española, no. 109, 257-272.

Ministerio de Fomento (2009) Atlas Estadístico de las Áreas Urbanas en España. [URL:

$<$ http://siu.vivienda.es/portal/index.php?option=com_content\&view=article\&id= 53\&Itemid=73\&lang $=$ es $>$. Consultado 12 de octubre de 2012].

Naredo, José Manuel, y Montiel, Antonio (2011) El Modelo Inmobiliario Español y su Culminación en el Caso Valenciano. Barcelona: Icaria Editorial.

Observatorio Metropolitano (Isidro López y Emmanuel Rodríguez) (2010) Fin de Ciclo. Financiarización, Territorio y Sociedad de Propietarios en la Onda Larga del Capitalismo Hispano (1959-2010). Madrid: Editorial Traficantes de Sueños.

Observatorio Metropolitano (2007) Madrid ¿La suma de todos? Globalización, territorio, desigualdad. Madrid: Ed. Traficantes de Sueños.

Ortiz, Pedro (1997) "La Ordenación reticulada del territorio (O.R.T.)". URBAN, nº $1,125-133$.

Rodríguez López, Julio (2006) "Los booms inmobiliarios en España: un análisis de tres períodos". Papeles de Economía Española, $\mathrm{n}^{\circ}$. 109, 76-90.

Rullán Salamanca, Onofre (1999) "La nueva Ley del Suelo de 1998 en el contexto del neoliberalismo postmoderno". Revista Investigaciones Geográficas, $\mathrm{n}^{\circ} .22$, 5-22.

Tribunal de Defensa de la Competencia (2005) La competencia en España: Balance y Nuevas propuestas. Madrid: Ed. Tribunal de Defensa de la Competencia,

Tribunal de Defensa de la Competencia (1993) Remedios Políticos que pueden favorecer la Libre Competencia en los servicios y atajar el daño causado por los monopolios. Madrid: Ed. Tribunal de Defensa de la Competencia. 